\title{
The Value of Continuous Power Supply for Flemish Households ${ }^{1}$
}

\author{
Guido Pepermans \\ Faculty of Economics and Management, HUBrussel \\ Economics Department, K.U.Leuven
}

(Draft version)

7 July 2010

\begin{abstract}
This paper estimates the willingness to pay of Flemish households for continuous power supply, based on a stated preference approach. The data were collected via choice experiments which were then used to estimate a set of logit models ranging from a main effects conditional logit model to random parameter logit model with interaction effects and correlated preferences. Power outages are characterized by 6 attributes: annual frequency, duration, peak or off peak, announced or unannounced, winter or summer and invoice impact. All estimates have the expected sign and are used to assess the marginal willingness to pay by Flemish households for each of these attributes. Overall, the estimates suggest that Flemish households have heterogeneous preferences regarding power outage attributes, and that a significant share of them is willing to switch to a lower reliability level if that would be compensated by a relatively small electricity bill discount.

We further illustrate i) how the model estimates can be used to assess the impact on a household's consumer surplus of a transition from an initial power outage state of the world (the status quo in the choice experiment) to a new state of the world, and ii) how the estimates can be used to assess the market potential of different power outage profiles if they would be offered for sale by electricity suppliers and/or distribution companies. Again, these illustrations show that some market potential exists for differentiated power outage contracts.

Keywords:

JEL-classification:

Corresponding Author:

Power outage, Willingness to pay, Survey, Choice experiment, Random parameter logit

$\mathrm{C} 25, \mathrm{C} 93, \mathrm{D} 12, \mathrm{Q} 41$

Guido Pepermans

Faculty of Economics and Management

HUBrussel

Stormstraat 2

1000 Brussels

Belgium

e-mail: guido.pepermans@hubrussel.be
\end{abstract}

1 The paper strongly benefited from the research project 'Embedded generation: a global approach to energy balance and grid power quality and security', financed by the Agency for Innovation by Science and Technology (IWT). 


\section{The Value of Continuous Power Supply for Flemish Households}

This paper assesses the role of attitudes, perceptions, consumer experience and socio-demographic characteristics on the willingness to pay for continuous power supply in Flanders (Belgium). In many European countries, the reliability of power supply was and still is very high, mainly because of the high engineering standards applied in the pre-liberalization era. As a result, customers and policy makers did not - and in many cases still do not - really care about supply interruptions as their occurrence is perceived be very unlikely. However, the recent past has shown a number of large power outages or black-outs in Europe, for example in Hungary (1999), Finland (2001), Italy (2003) and Sweden (2005).

Belgium has had relatively little experience with large scale power outages, an observation that is supported by the power outage statistics presented in Figure 1 and Figure 2. Together with The Netherlands, it is among the best performing European countries when it comes to the reliability of power supply. Figure 3 and Table 1 present more detailed data for the Flemish region, the northern part of Belgium. The average number of minutes with a power interruption per year and per customer served (SAIDI) is about 23 minutes (Table 1), which is well below the number of minutes reported by most other European countries ${ }^{2}$. This table also illustrates the variability of the SAIDI within Flanders, i.e. between the Flemish distribution areas. Figure 3 illustrates the same variability.

Power supply interruptions are usually due to exceptional events, but some argue that in the near European future the number of interruptions might also increase for reasons related to the economic context. This view is based on the argument that the recent liberalization of the energy markets induces generators and system operators to become more cost efficient, which might result in reduced maintenance and investment outlays. Increased competitive and regulatory pressure creates incentives for cost-savings which might result in a deterioration of reliability levels (Ajodhia and Hakvoort (2005)).

Whether this is good or bad remains to be seen. The Council of European Energy Regulators (2009) correctly states that 'The design and operation of the power system should be such that the number and duration of interruptions is acceptable to most customers, without incurring unacceptably high costs'. Finding a balance between reliability and costs remains one of the major challenges for the electricity sector, but it should, for example, also be recognized that the optimal reliability level can be different for different customers and for different regions. Put differently, it might be possible that some customer groups are willing to accept a lower reliability level if that would imply a reduction in their cost of electricity. From a social point of view, this would be beneficial, as it would

\footnotetext{
The Flemish data concern incidents reported at the mid voltage level. Data on power outages at the low voltage level are currently not available. This can have a significant impact on the reported indices. Although the impact of an interruption in terms of number of customers affected is much smaller at the low voltage level, the duration of an interruption is usually much longer. To illustrate the potential impact: the Council of European Energy Regulators (2009) reports that in Italy about 7\% of SAIFI and 22\% of SAIDI (measured between 1999 and 2007) is due to incidents at the low voltage level. In Hungary, 19\% of SAIFI and 30\% of SAIDI were due to incidents at the LV level ((measured between 2003 and 2006).

Most countries differentiate their reliability indices per voltage level. However, the definition of the different voltage levels also tends to differ between countries. This makes it very difficult to compare reliability indices between countries.
} 
result in cost savings in terms of investments in power and grid infrastructure. Furthermore, expenditures on improved power quality could be targeted to those customers that actually require continuous supply and that are willing to pay a premium for this service. For example, having a continuous power supply is important for industries like the chemical, petroleum, refining, paper, metal or telecommunications industry. But despite the good Flemish records regarding reliable electricity supply, we do indeed observe that many firms operating in these sectors invest in additional backup generation or uninterruptible power supply devices. Targeting investments and efforts to these companies might be more efficient than improving the overall efficiency and reliability of the power grid.

Also, reliability requirements for the grid can evolve over time as electric equipment changes and new technologies emerge that allow for on-site solutions for reliability risks. In general, the energy market liberalization makes market players more aware of the value of having and the cost of providing reliable electricity. The efficiency of the market would benefit if that value would be taken into account when designing the future power system.

This paper focuses on the Flemish residential sector and assesses its willingness to pay for continuous power supply under varying conditions. Investments in backup equipment and in UPS devices are less frequently found in the residential sector, which in itself can be seen as an indication that the residential sector puts less value on continuous power supply than some industries do. However, about $25 \%$ of electricity is consumed by the residential sector which makes it sufficiently important to investigate in terms of willingness to pay for continuous supply.

It is our conjecture that the efficiency of the electricity system can be improved by a more personalized approach in terms of reliability levels offered to customers. We feel that a vast number of residential customers are willing to accept lower reliability levels if adequate compensation is offered $^{3}$. The main objective of this paper is to estimate the level of compensation that would be required to counterbalance for these reduced reliability levels, conditional upon different characteristics of a power outage (such as the timing and announcement characteristics, duration and the frequency of the power outages). At the same time, these estimates also indicate the willingness to pay (WTP) by Flemish households for increased reliability levels.

Finding the appropriate compensation level requires knowledge about preferences on continuous power supply. This kind of information can be derived from revealed behavior or from stated behavior ${ }^{4}$. See Munasinghe and Sanghvi (1988) and Serra and Fierro (1997) for a survey of papers on this topic in the area of continuous power supply. In the past, the revealed preference approach was used more frequently, but more recently the focus has shifted to using stated preferences data, i.e. data collected via surveys in which respondents are asked to assess hypothetical situations. This is also the approach followed in this paper. We construct a choice experiment (CE) in which we confront respondents with a number of hypothetical power outage profiles, containing different combinations of outage attributes or characteristics (frequency, duration, timing...). The respondent is then asked to indicate the profile that he or she prefers. The approach comes close to a real

\footnotetext{
This would be similar what is already available in many industries via interruptible electricity contracts. Moreover, the introduction of smart grids would make such contracts relatively easy to implement.

4 For a further and more elaborate discussion of the relative strengths and weaknesses of the various revealed and stated preferences approaches we refer to Hsu et al. (1994). That paper also explains why the estimated outage costs may differ according to the approach or method that is used.
} 
market situation as respondents effectively have to make a choice and one of the major advantages is that, by describing a power outage profile in terms of attributes and attribute levels, the relative importance (value) of the different attributes can be assessed.

To assess the WTP for continuous power supply (or the willingness-to-accept (WTA) power outages) we estimate a discrete choice model. Conjoint choice data are typically analyzed with a logit model, see for example Beenstock et al. (1998). As Train (2003) and Moore (2008) point out, one drawback of the standard logit model is that homogenous preferences are assumed. Logit models tackle heterogeneity only to the extent that it is explained, for example, by interacting demographic or household characteristics with the attributes of the product under consideration. Therefore, in this paper, we estimate a heterogeneous preference model, more specifically a Random Parameters or mixed logit model (RPL) (Train (2003)). Over the past years, the number of applications of RPL models has increased, e.g. Carlsson and Martinsson (2008) for preferences for continuous power supply in Sweden. As explained by Moore (2008) one drawback of the standard RPL model is that, although heterogeneous preferences are allowed for, the sources of heterogeneity often remain unexplored. This could easily be handled by estimating the distribution of the random preference parameters conditional upon individual characteristics. See Morey and Rossmann (2003) and Moore (2008) for illustrations of this approach. In this paper, we follow a similar approach by conditioning the distribution of the preference parameters on individual characteristics but also on information regarding attitudes, perception and past experience.

Although the choice experiment approach does not provide direct estimates of the WTP, it can be estimated indirectly via the parameters of the estimated model. Furthermore, estimating an RPL model also allows obtaining individual specific WTP estimates, which then allows analyzing the distribution of the WTP values in the population. See, for example, Carlsson and Martinsson (2006) and Carlsson and Martinsson (2008).

Alternatively, heterogeneous preferences could also be introduced via a latent class model along the lines of Morey et al. (2006) or Boxall and Adamowicz (2002). Morey et al. (2006) considers both attitudes and choices as expressions of (exogenous) underlying preferences. Therefore, group or class membership is exogenous. On the contrary, Boxall and Adamowicz (2002) assume that attitudes determine group membership. In their view, group or class membership is endogenous. Moore (2008) compares the three modeling approaches and concludes that assuming heterogeneous preferences adds to the explanatory power of the models. Furthermore, despite differences in the underlying assumptions and in the parameter estimates, the WTP-estimates derived from the three models show little difference. Therefore, from a policy perspective the main message is that it does not matter how attitudinal data are included in empirical models, as long as they are included.

The major contributions of our paper are i) estimating household preferences for continuous power supply by applying a stated preferences approach to the Flemish electricity market, while ii) assessing the role of the respondent's personal characteristics, including attitudes, perceptions and past experience by iii) assuming heterogeneous preferences regarding continuous power supply. While a number of papers have already studied the role of attitudes and perception in further reducing unexplained preference heterogeneity, this paper is - to our knowledge - the first one to consider this issue in the context of continuous (residential) power supply.

The structure of the paper is as follows. Section 1 briefly presents the RPL model and its underlying assumptions. Section 2 describes the data collection process and the data that are available. Section 
3 presents estimates of the preference parameters for four models, ranging from a simple conditional main effects logit model to a RPL model with interaction effects and correlated preferences. Section 4 then presents WTP/WTA estimates for changes in power outage attribute levels and their distribution in the Flemish population. Moreover, this section also assesses the welfare effect at the individual level of creating a market for power outage profiles. That is, a market where households can buy a suitable power outage profile from their electricity supplier. Finally, section 5 concludes.

\begin{tabular}{|c|c|c|c|c|c|c|}
\hline \multicolumn{7}{|c|}{$\begin{array}{l}\text { System Average Interruption Duration Index (SAIDI - minutes per customer served) } \\
\text { (Sum of all customer interruption durations/total number of customers served) }\end{array}$} \\
\hline & 2003 & 2004 & 2005 & 2006 & 2007 & Average \\
\hline Min & 6,85 & 8,63 & - & 0,00 & 9,08 & 9,60 \\
\hline Weighted average & 21,78 & 22,22 & - & 28,22 & 22,19 & 18,88 \\
\hline Max & 86,92 & 88,53 & - & 71,00 & 98,65 & 84,15 \\
\hline Wtd St. Dev. & 6,87 & 8,64 & - & 11,11 & 8,21 & 8,04 \\
\hline \multicolumn{7}{|c|}{$\begin{array}{l}\text { System Average Interruption Frequency Index (SAIFI - interruptions per customer served) } \\
\text { (total number of customer interruptions/total number of customers served) }\end{array}$} \\
\hline & 2003 & 2004 & 2005 & 2006 & 2007 & Average \\
\hline Min & 0,280 & 0,271 & - & 0,000 & 0,225 & 0,354 \\
\hline Weighted average & 0,555 & 0,527 & - & 0,679 & 0,556 & 0,579 \\
\hline Max & 1,655 & 1,646 & - & 1,459 & 1,870 & 1,658 \\
\hline Wtd St. Dev. & 0,195 & 0,166 & - & 0,194 & 0,160 & 0,157 \\
\hline \multicolumn{7}{|c|}{$\begin{array}{l}\text { Customer Average Interruption Duration Index (CAIDI -minutes per customer affected) } \\
\text { (Sum of all customer interruption durations/total number of customers interrupted) }\end{array}$} \\
\hline & 2003 & 2004 & 2005 & 2006 & 2007 & Average \\
\hline Min & 18,00 & 21,47 & - & 0,00 & 26,62 & 23,50 \\
\hline Weighted average & 40,93 & 41,78 & - & 40,62 & 39,57 & 32,58 \\
\hline $\operatorname{Max}$ & 66,00 & 60,12 & - & 84,00 & 63,05 & 61,00 \\
\hline Wtd St. Dev. & 10,03 & 11,57 & - & 10,21 & 7,22 & 8,74 \\
\hline
\end{tabular}

Table 1: Aggregate power outage data for Flanders. 


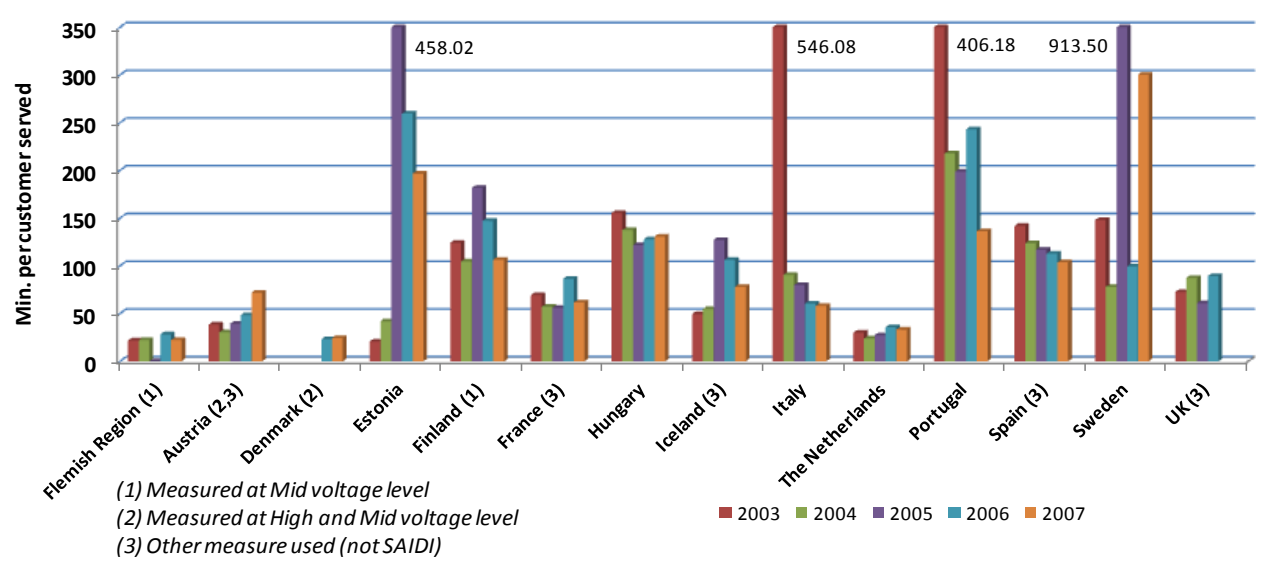

Figure 1: SAIDI for some European countries (at HV, MV and LV) ${ }^{5}$.

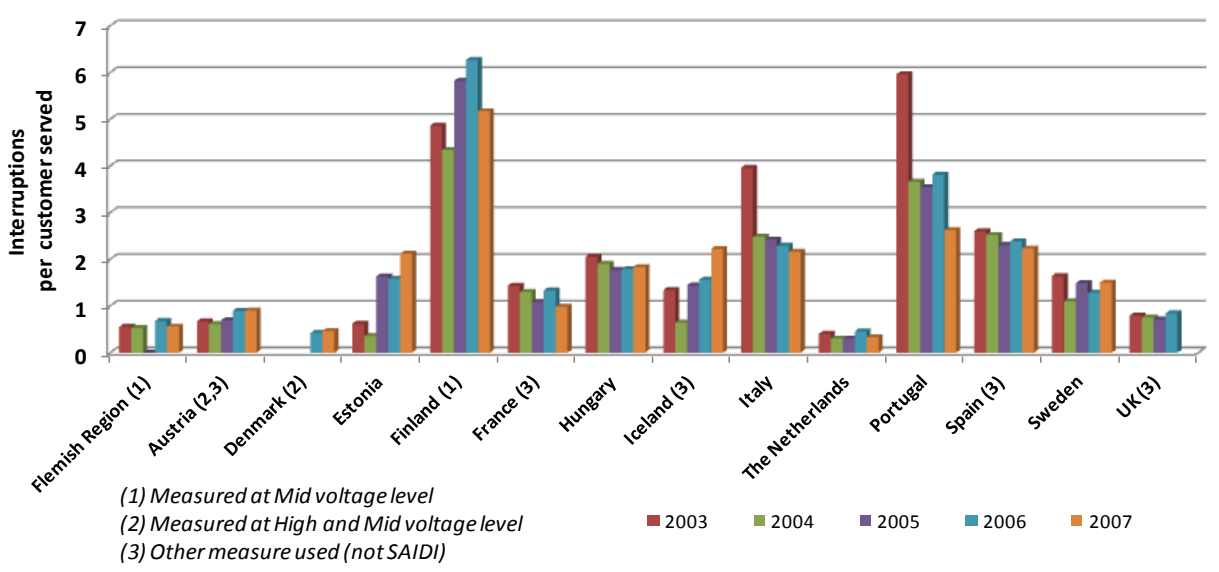

Figure 2: SAIFI for some European countries (at HV, MV and LV).

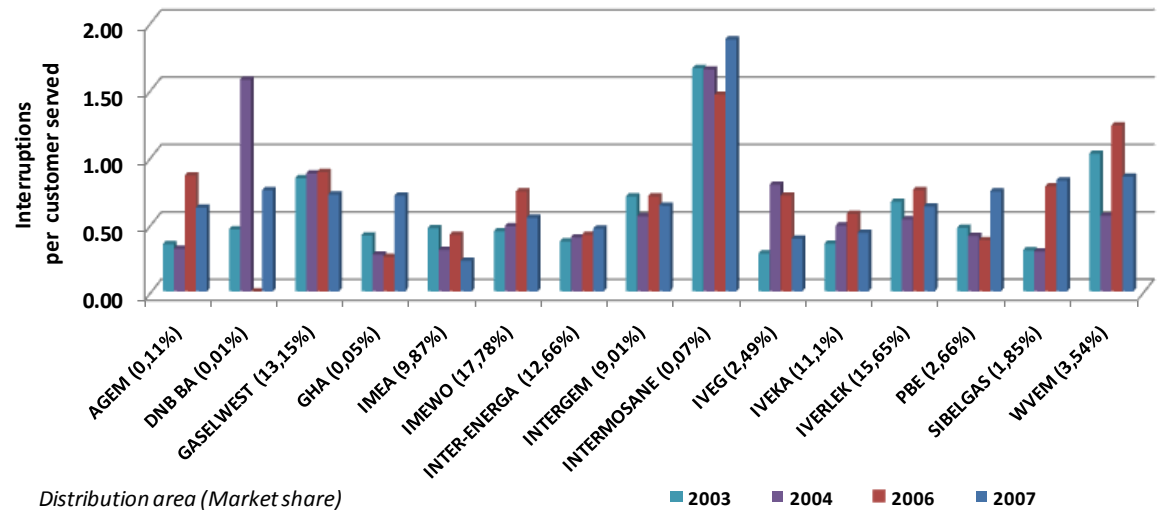

Figure 3: SAIFI for the Flemish distribution companies (at MV). 


\section{The Model}

We use a Random Utility Model (RUM) to analyze household preferences. The RUM is based on random utility theory which starts from the assumption that decision units maximize utility, i.e. when a decision maker is faced with a set of different alternatives, he or she will always choose the one with the highest utility. Let the decision unit $n$ face $T$ consecutive choice problems each of which implies a choice to be made between $J$ alternatives. From each of the alternatives $j$ a utility level $U_{n j t}$ can be obtained, which is known to the decision unit but is only partially observed by the researcher, i.e.

$$
U_{n j t}=V_{n j t}+\varepsilon_{n j t}
$$

with $V_{n j t}$ observed utility and $\varepsilon_{n j t}$ unobserved utility, represented as a random term. For each choice problem $C$, a decision unit will select the alternative that provides maximal utility. Thus, at time $t$ alternative $j$ is chosen by decision unit $n$ when

$$
U_{n j t}>U_{n i t} \quad \forall i \neq j \in C
$$

Due to the presence of the random component in equation (1) only probabilistic statements can be made about the respondent's choices. The probability of choosing alternative $j$ from choice set $C$ can be written as

$$
\begin{aligned}
P(j \mid C) & =P\left(U_{n j t}>U_{n i t}, \quad \forall i \neq j \in C\right) \\
& =P\left(V_{n j t}+\varepsilon_{n j t}>V_{n i t}+\varepsilon_{n i t}, \quad \forall i \neq j \in C\right) \\
& =P\left(\varepsilon_{n i t}<\varepsilon_{n j t}+V_{n j t}-V_{n i t}, \quad \forall i \neq j \in C\right)
\end{aligned}
$$

Assume that $\varepsilon_{n j t}$ is i.i.d. type I extreme value. It can then be shown that, for decision unit $n$, the probability of choosing $j$, when faced with choice set $C$ at time $t$, equals

$$
P_{n j t}=\frac{e^{V_{n j t}}}{\sum_{i \in C} e^{V_{n i t}}} .
$$

Usually, observed utility is assumed to be linear in the parameters, i.e.

$$
V_{n j t}=\beta x_{n j t} \text {, }
$$

with $x_{n j t}$ a vector of alternative-specific attributes and $\beta$ the vector of parameters to be estimated. Equations (4) and (5) define the conditional logit model. Note that the parameter vector is not indexed, implying that preferences are assumed to be homogeneous. This is a rather extreme assumption that can be relaxed by allowing tastes to vary over the population with density $f(\beta)$ (Train (2003)). We can then rewrite equation (5) as

$$
V_{n j t}=\beta_{n} x_{n j t}
$$

where the heterogeneity of preferences is now made explicit by indexing $\beta$. Note that $\beta_{n}$ is assumed constant over time, i.e. preferences of decision unit $n$ are stable over consecutive choice situations, which for the current application is a realistic assumption. However, as will become clear in section 3.1, we will allow $\beta_{n}$ to vary with personal characteristics of the decision unit (demographic variables, attitudes, experience....). 
In this paper, we assume preferences to follow a normal density, i.e. $\beta_{n}=\mu_{\beta}+\eta_{n}$ with $\beta_{n} \sim N\left(\mu_{\beta}, \Sigma_{\beta}\right)$ or $\eta_{n} \sim N\left(0, \Sigma_{\eta}\right)$ where $\eta_{n}$ is a vector of individual-specific deviations that are assumed to be normally distributed with mean 0 and covariance matrix $\Sigma_{\eta}$. A decision unit knows his own $\beta_{n}$ when choosing an alternative, but the researcher does not. Conditional on $\beta_{n}$, the probability of decision unit $n$ choosing alternative $j$ at time $t$ is

$$
L_{n j t}\left(\beta_{n}\right)=\frac{e^{\beta_{n} x_{n j t}}}{\sum_{i \in C} e^{\beta_{n} x_{n i t}}} .
$$

Knowing that $\varepsilon_{n j t}$ is i.i.d. extreme value over decision units, alternatives and time, we can write the conditional probability that a decision maker will make a given sequence of choice $\mathbf{j}=\left\{j_{1}, j_{2}, \ldots, j_{T}\right\}$ as

$$
\mathbf{L}_{n \mathrm{j}}\left(\beta_{n}\right)=\prod_{t=1}^{T} \frac{e^{\beta_{n} x_{n j t}}}{\sum_{i \in C} e^{\beta_{n} x_{n i t}}}
$$

As the researcher does not know $\beta_{n}$, he or she has to consider all possible values of $\beta$ to arrive at the unconditional choice probability of decision unit $n$ choosing the sequence of alternatives $\mathbf{j}$ :

$$
\begin{gathered}
P_{n \mathrm{j}}=\int \mathbf{L}_{n \mathrm{j}}(\beta) f\left(\beta \mid \mu_{\beta}, \Sigma_{\beta}\right) d \beta \\
P_{n \mathrm{j}}=\int \prod_{t=1}^{T} \frac{e^{\beta x_{n j t} t}}{\sum_{i \in C} e^{\beta x_{n i t}}} f\left(\beta \mid \mu_{\beta}, \Sigma_{\beta}\right) d \beta .
\end{gathered}
$$

Equation (8) cannot be solved analytically, but simulation techniques can be used to solve for the preference parameters that maximize the simulated log-likelihood function ${ }^{6}$ (Train (2003)).

\section{The Data}

The analysis in this paper focuses on the Flemish residential sector and is based on survey data collected from 1488 households in the period November 2004 to January 2005. The Flemish region is the Dutch speaking northern part of Belgium. Early 2005, Flanders counted just over 6 million inhabitants and about 2,5 million households.

The first part of the survey collects information about the respondent's experience with power outages. These questions also prepare the respondent for the choice experiment question in the second part of the questionnaire by forcing them to think about the issue of continuous power supply, about past experiences and the possible consequences of power outages. In the second part we collect information on the respondent's attitude towards power outages and electricity markets in general. This part also contains 12 choice experiment questions. Finally, the third part collects information on relevant socio-demographic characteristics (such as household size, education, energy dependence, income level...). On average, it took about 36 minutes to fill in the questionnaire.

\footnotetext{
6 Actual estimations were done with STATA's mixlogit procedure.
} 
Table 2 and Table 3 summarize information on experience, attitude and market data as obtained from the survey. The upper part of Table 2 reports on experience with power outages. The reported average annual number of power outages is 0,91 , which is about twice as high as the annual number of power outages reported by the VREG (see Table 1, SAIFI). Clearly, both numbers cannot easily be compared as the frequency reported by the VREG concerns power outages emerging at the mid voltage level, while the reported number in the table below includes all power outages, irrespective of the voltage level at which the outage is induced ${ }^{7}$. Just over $20 \%$ of households explicitly report zero power outages over the past two years (not in the table). More than $75 \%$ of the respondents report 2 or less power outages in two years time, less than $5 \%$ of households were hit by at least 5 outages over the past two year before the survey date.

On average, respondents were disconnected from power supply for just over 100 minutes per year, which is about 2,5 times as much as reported by the VREG (see Table 1, CAIDI). About $5 \%$ of households reported a total duration of power outages of more than 5 hours per year (not in the table). For $25 \%$ of the households, the average annual duration of power outages was less than 23 minutes. Again, note that these responses also include outages that are induced at the lower voltage level, which might to large extent explain the difference with the reported VREG data.

According to the respondents, most of the reported power outages were unannounced. The median response was zero announced power outages, i.e. more than $50 \%$ of the respondents claim that they did not receive any advance notice for any of the power outages they incurred.

\begin{tabular}{|c|c|c|c|c|c|c|}
\hline Experience $^{a}$ & & & & & & \\
\hline & Average & $1^{\text {st }} Q$ & Median & $3^{\text {th }} Q$. & SD & $\mathbf{N}$ \\
\hline Number of PO experienced over the past 2 years? & 1,82 & 1 & 1 & 2 & 1,93 & 1195 \\
\hline Number of minutes hit by $\mathrm{PO}$ over the past 2 years? & 209,16 & 45 & 120 & 240 & 398,26 & 923 \\
\hline If remembered, how many PO were announced? & 0,75 & 0 & 0 & 1 & 2,15 & 718 \\
\hline \multicolumn{7}{|l|}{ Attitude $^{a}$} \\
\hline & Average & $1^{\text {st }} Q$ & Median & $3^{\text {th }} Q$. & SD & $\mathbf{N}$ \\
\hline $\begin{array}{l}\text { Starting from how many PO per year would you say } \\
\text { that your electricity company is performing below } \\
\text { acceptable standards? }\end{array}$ & 2,66 & 1 & 2 & 4 & 3,30 & 1.410 \\
\hline \multicolumn{7}{|l|}{ Market data ${ }^{a}$} \\
\hline & Average & $1^{\text {st }} Q$ & Median & $3^{\text {th }} Q$. & SD & $\mathbf{N}$ \\
\hline Electricity consumption over the past year (kWh) & 4.618 & 2.233 & 3.450 & 5.373 & 4.046 & 1.065 \\
\hline Electricity bill $(€)$ & 636 & 352 & 533 & 789 & 443 & 1.065 \\
\hline
\end{tabular}

Table 2: Descriptive statistics for continuous experience, attitude and market data.

The survey also contained a question about the acceptable annual number of power outages for the household. More than half of the Flemish households consider at most 2 power outages per year as acceptable and more than $25 \%$ considers more than 3 power outages per year as acceptable. On average, 2,7 power outages per year are considered acceptable, which is largely above the reported frequency of power outages, which was less than one per year. This suggests that a significant fraction of the residential sector might easily be convinced to accept a reduction in the reliability level of power supply.

\footnotetext{
In the survey, power outages are defined as 'any interruption of power supply (i.e. voltage drop to zero) with a duration from a few seconds to even days that impacts your dwelling, but also your neighbor's dwelling. It is explicitly stated that a blown fuse in the respondent's house is not considered as a power outage as defined for the survey.
} 
In the survey, average electricity consumption was $4.618 \mathrm{kWh}$ per year per household, for which on average $€ 636$ was paid.

In Table 3 we report some statistics on categorical data related to experience, attitudes and the market. The vast majority of households $(73,4 \%)$ reported that no material damages were experienced due to the power outages that hit them.

About $65 \%$ of households considers the annual number of power outages that strikes them 10,93 on average) as low to very low. This also supports the previously suggested hypothesis that a relaxation of reliability levels might be acceptable for a large group of households. When asked about what one expects to happen with the future reliability level of power supply, about $71 \%$ of households do not expect any change. From those that do expect a change in the reliability level, the majority $(14,5 \%)$ thinks that reliability levels will increase. When asked whether one would be willing to pay for an increased reliability level, $75 \%$ of households answers negative, almost $9 \%$ answers positive, and $16,2 \%$ does not know. Almost $21 \%$ of households would accept reduced reliability levels if this would imply a financial compensation, while $66 \%$ would not accept reduced reliability levels. Again, we observe that households are more inclined to accept a reduction of the reliability level rather than an increase. This should not be very surprising, as it is well known from the literature that WTA is usually substantially higher than WTP. See for example Horowitz and McConnell (2002).

When asked about an appropriate period of advance notice, about $34 \%$ of households respond that 1 working day would be appropriate, while $40,4 \%$ considers 3 working days as appropriate.

Households were also asked to reflect upon the per kWh price level for electricity consumed during the day (in 2004, this was about $€ 0,15$ including VAT). More than $60 \%$ of households consider this a high to very high price per kWh, while about one third of households consider it to be a fair price.

Table 3 also provides some insight in the demographic, geographical and market characteristics of the sample. About $85 \%$ of households own the house they live in. About $43 \%$ of households report to live in an urban area, while almost $69 \%$ is living in a city center.

When asking about their electricity supplier, $19 \%$ of households report to have switched away from one of the two default suppliers ${ }^{8}$. At the time of the survey, almost $60 \%$ did not switch but decided to sign a contract with their default supplier. Only $6 \%$ of households state that looking for another supplier is not worth the effort, despite the fact that about $45 \%$ of households perceive their electricity bill as high to very high.

Finally, information about the (major) heating system is also reported as this might help to explain why respondent are (not) willing to accept reduced reliability levels in power supply. About $13 \%$ of households report to heat their house with an electric heating device.

Overall, the data seem to provide some support for the idea that a reduced reliability level might be acceptable for a non-negligible fraction of households in return for a financial compensation.

\footnotetext{
Two default suppliers are operating in the Flemish market, Electrabel Customers Solutions and Luminus. These were the suppliers in the market before the move to liberalized markets. After opening the residential market for competition, all residential customers were by default assigned to their old supplier (the default supplier). Customers could then either do nothing, switch to another supplier or explicitly decide to stay with their default supplier, by signing a contract with that supplier.
} 


\begin{tabular}{|c|c|c|c|c|c|c|c|}
\hline Experience & & & & & & & \\
\hline \multirow[t]{3}{*}{$\begin{array}{l}\text { Damage incurred by a PO (past } 2 \\
\text { years)? }(N=884)\end{array}$} & Yes & No & $\begin{array}{l}\text { Don't } \\
\text { know }\end{array}$ & Missing & & & \\
\hline & 32 & 649 & 27 & 176 & & & \\
\hline & $3,0 \%$ & $73,4 \%$ & $3,1 \%$ & $19,9 \%$ & & & \\
\hline \multicolumn{8}{|l|}{ Attitude, Perception } \\
\hline Do you find the annual number of $P O s$ & Very low & Low & Average & High & Very high & No opinion & Missing \\
\hline \multirow{2}{*}{ in your house...? $(N=884)$} & 338 & 242 & 78 & 35 & 5 & 8 & 178 \\
\hline & $38,2 \%$ & $27,4 \%$ & $8,8 \%$ & $4,0 \%$ & $0,6 \%$ & $0,9 \%$ & $20,1 \%$ \\
\hline In the coming years, will the likelihood & Decrease & No change & Increase & Missing & & & \\
\hline \multirow[t]{2}{*}{ of $a P O \ldots ?(N=1065)$} & 90 & 755 & 154 & 66 & & & \\
\hline & $8,5 \%$ & $70,9 \%$ & $14,5 \%$ & $6,2 \%$ & & & \\
\hline $\begin{array}{l}\text { Would you be willing to pay more if } \\
\text { your electricity company decreased }\end{array}$ & Yes & No & $\begin{array}{l}\text { Don't } \\
\text { know }\end{array}$ & Missing & & & \\
\hline the likelihood of being hit by a PO? & 92 & 799 & 173 & 1 & & & \\
\hline$(N=1065)$ & $8,6 \%$ & $75,0 \%$ & $16,2 \%$ & $0,1 \%$ & & & \\
\hline $\begin{array}{l}\text { Would you accept an increased } \\
\text { likelihood of being hit by a PO if your }\end{array}$ & Yes & No & $\begin{array}{l}\text { Don't } \\
\text { know }\end{array}$ & Missing & & & \\
\hline electricity company would decrease & 219 & 706 & 140 & - & & & \\
\hline your electricity bill? $(N=1065)$ & $20,6 \%$ & $66,3 \%$ & $13,1 \%$ & & & & \\
\hline \multirow[t]{3}{*}{$\begin{array}{l}\text { How long in advance outage would } \\
\text { you want to be informed? }(N=1065)\end{array}$} & 4 hours & $\begin{array}{l}1 \text { work. } \\
\text { Day }\end{array}$ & $\begin{array}{l}3 \text { work. } \\
\text { days }\end{array}$ & $\begin{array}{l}5 \text { work. } \\
\text { days }\end{array}$ & Don't care & Missing & \\
\hline & 25 & 362 & 430 & 210 & 27 & 11 & \\
\hline & $2,3 \%$ & $34,0 \%$ & $40,4 \%$ & $19,7 \%$ & $2,5 \%$ & $1,0 \%$ & \\
\hline \multirow{3}{*}{$\begin{array}{l}\text { Would you say the per kWh-price for } \\
\text { electricity used during the day is...? } \\
(N=1065)\end{array}$} & Very low & Low & Average & High & Very high & No opinion & Missing \\
\hline & & 6 & 348 & 522 & 123 & 49 & 17 \\
\hline & $0,0 \%$ & $0,6 \%$ & $32,7 \%$ & $49,0 \%$ & $11,5 \%$ & $4,6 \%$ & $1,6 \%$ \\
\hline \multicolumn{8}{|l|}{ Market data } \\
\hline \multirow[t]{3}{*}{ House owner? $(N=1065)$} & Yes & No & Missing & & & & \\
\hline & 908 & 154 & 3 & & & & \\
\hline & $85,3 \%$ & $14,5 \%$ & $0,3 \%$ & & & & \\
\hline \multirow[t]{3}{*}{ Living in urban area? $(N=1065)$} & Yes & No & Missing & & & & \\
\hline & 455 & 605 & 5 & & & & \\
\hline & $42,7 \%$ & $56,8 \%$ & $0,5 \%$ & & & & \\
\hline \multirow{3}{*}{ Living in a city center? $(N=1065)$} & Yes & No & Missing & & & & \\
\hline & 729 & 335 & 1 & & & & \\
\hline & $68,5 \%$ & $31,5 \%$ & $0,1 \%$ & & & & \\
\hline \multirow[t]{3}{*}{$\begin{array}{l}\text { Switched away from standard supplier } \\
\text { or signed contract? }(N=1065)\end{array}$} & Yes & $\begin{array}{l}\text { No, signed } \\
\text { contract }\end{array}$ & $\begin{array}{l}\text { Will } \\
\text { consider } \\
\text { soon }\end{array}$ & $\begin{array}{l}\text { Not worth } \\
\text { the effort }\end{array}$ & Missing & & \\
\hline & 201 & 632 & 152 & 65 & 15 & & \\
\hline & $18,9 \%$ & $59,3 \%$ & $14,3 \%$ & $6,1 \%$ & $1,4 \%$ & & \\
\hline & Very low & Low & Average & High & Very high & No opinion & Missing \\
\hline \multirow[t]{2}{*}{ electricity bill is...? $(N=1065)$} & 7 & 42 & 511 & 390 & 86 & 18 & 11 \\
\hline & $0,7 \%$ & $3,9 \%$ & $48,0 \%$ & $36,6 \%$ & $8,1 \%$ & $1,7 \%$ & $1,0 \%$ \\
\hline Is your house heated with electric & Yes & No & Missing & & & & \\
\hline \multirow[t]{2}{*}{ heating? $(N=1065)$} & 142 & 886 & 37 & & & & \\
\hline & $13,3 \%$ & $83,2 \%$ & $3,5 \%$ & & & & \\
\hline
\end{tabular}

Table 3: Descriptive statistics for categorical experience, attitude and market data.

\section{The choice experiment}

At the basis of the choice experiment approach is the idea that any good or service can be described by its characteristics or attributes and by the levels that these attributes take ${ }^{9}$. We selected 6 attributes to describe a power outage, based on what is commonly found in the literature and on a pilot survey. Table 4 lists the attributes and levels used in the survey.

\footnotetext{
9 We refer to Bateman et al. (2002) and Amaya-Amaya et al. (2008) for a more elaborate discussion of the CE technique.
} 


\begin{tabular}{lll|}
\multicolumn{1}{c}{ Attribute } & \multicolumn{1}{c|}{ Description } & \multicolumn{1}{c|}{ Levels } \\
\hline Frequency & Number of outages per year & $1,2,4$ \\
Duration & Average duration of one outage in minutes & $15,60,240$ \\
Season & Period of the year & Winter $^{1}$, Summer $^{1}$ \\
Timing & Period of the day & Peak $^{2}$, Off peak \\
Announced & Was there advance notice & Yes, No \\
Bill impact & Percentage change in the annual bill & $-10 \%, 0,+10 \%$ \\
\hline 1 & Summer: from April to September. Winter: from October to March. \\
2 & Peak: on weekdays between 7am and 9am and between 5pm and 10pm. Off peak: on \\
\cline { 2 - 3 } & weekdays between 9am and 5pm and between 10pm and 7am. The weekend
\end{tabular}

Table 4: Attributes and levels.

A full factorial design comprises $3^{3} \times 2^{3}=216$ different scenarios. Obviously, it would have been too complicated for respondents to evaluate all possible power outage scenarios. Therefore, only a subset of scenarios was presented to and evaluated by the respondents. Obviously, this affects the amount of information that can be collected. Whereas a full factorial design would allow unbiased estimation of all possible main and interaction effects in a linear model, a fractional factorial design will only allow estimating some of these effects, probably in a biased way. Which effects can be estimated and which ones will be biased depends on the constructed fractional factorial design (Louvière et al. (2003)). We constructed a design that allowed estimating all main and first-order interaction effects, while giving maximal consideration to balancing and orthogonality ${ }^{10}$. All choice sets contained 3 power outage scenarios and the status quo alternative. Each respondent had to evaluate 12 choice sets. In total, 24 blocks or versions of the questionnaire were created, each containing 12 choice sets. Each block was filled in by approximately 60 respondents.

\section{Model specification and estimation}

Provencher and Bishop (2004) show that more complex models do not necessarily result in better out-of-sample forecasts compared to simpler logit models. We therefore present estimation results for a range of models, starting with a main effects conditional logit model and increasing complexity up to a mixed logit model including interaction effects and covariates related to household attitudes, perceptions and experience regarding power outages. See Table 5 for a brief description of the models. All model estimates are based on the same set of 32.408 observations, collected from 603 households ${ }^{11}$. As noted before, one advantage of the stated preference approach is that it allows collecting multiple observations per respondent. As explained in section 2, respondents were asked to evaluate 12 choice sets, each containing 3 alternatives and the status quo ${ }^{12}$. The estimation results are grouped in Table 8.

The random parameters in the mixed logit model were selected by applying the procedure proposed by McFadden and Train (2000) and carefully explained by Hensher and Greene (2003). The procedure works by constructing artificial variables $z_{i n}=\left(x_{i n}-\bar{x}_{n}\right)^{2}$ with $\bar{x}_{n}=\sum_{j} x_{j n} P_{j n}$, with $P_{j n}$ the conditional logit choice probabilities, $i, j$ the alternatives and $n$ a household index. The conditional logit model is then re-estimated, including the artificial variables as explanatory variables. The null

\footnotetext{
10 The efficiency of the fractional factorial design was evaluated with SAS v8.2. This software was also used to select the number of choice sets and the number of alternatives per choice set and to create the choice sets. A thorough discussion and many detailed examples are found in Kuhfeld (2004).

11 Note that this is substantially less than the original sample size of 1488 households. The difference is due to the presence of missing values in at least one of the variables used for the estimation of the correlated RPL model (see section 3.1).

12 Some households were asked by the survey company to evaluate a second block of 12 choice sets in order to obtained the contracted net sample of 1488 households, equally divided over the 24 versions of the questionnaire.
} 
hypothesis of no random effect is rejected when the estimated coefficient for the artificial variables is significantly different from zero. On the basis of this procedure we conclude that all attributes i.e. the frequency and duration of a power outage, season, peak versus off-peak and announcement - should have a random parameter. The procedure also suggests that the bill-attribute should have a random parameter. However, we decided to estimate a fixed bill parameter in order not to complicate the estimation of the willingness to pay values (Hensher and Greene (2003)).

\begin{tabular}{l|l}
\hline \multicolumn{1}{c|}{ Model } & \multicolumn{1}{c}{ Description } \\
\hline CL_Main & $\begin{array}{l}\text { Conditional logit model including alternative specific constants and main effects for all power } \\
\text { outage attributes. } \\
\text { Conditional logit model including alternative specific constants, main and interaction effects for all } \\
\text { power outage attributes and attribute interactions with attitude, perception, experience and } \\
\text { demographic covariates. } \\
\text { Random parameter logit model including alternative specific constants, main and interaction } \\
\text { effects for all power outage attributes and attribute interactions with attitude, perception, } \\
\text { experience and demographic covariates. } \\
\text { Random parameter logit model with correlated random effects including alternative specific } \\
\text { constants, main and interaction effects for all power outage attributes and attribute interactions } \\
\text { with attitude, perception, experience and demographic covariates. }\end{array}$ \\
\hline
\end{tabular}

Table 5: Description of the estimated models.

All random parameters are assumed to be normally distributed. For the qualitative attributes (season, timing and announcement) the choice is based on the empirical distributions of the individual parameters, estimated by applying the procedure described by Hensher and Greene (2003). The same procedure suggests that for the attributes 'frequency' and 'duration', a lognormal distribution might be more appropriate. However, convergence issues and reported experience related to estimating WTP values led us to assume normal densities for these random parameters. The latter motivation relates to the fact that WTP estimates based on random parameters following a lognormal distribution might take unreasonable values due to the very long right-hand tail (Hensher and Greene (2003)).

\subsection{Model specification}

Observed utility is specified as a linear function of power outage attributes (number $(N)$ and length $(L)$ of power outages, Peak/off-peak $(P)$, Season $(S)$, announcement $(A)$ and Bill $(B)$ ), attribute interactions and interactions of attitude, perception, experience, socio-demographic and income variables with these attributes. In its most general form, utility $U_{\text {nit }}$ for individual $n$ of alternative $i$ in choice set $t$, is written as (the subscript $n$ is omitted to simplify notation):

$$
\begin{aligned}
U_{i t} & =\beta_{i}^{C} A S C_{i} \\
& +\left(\beta_{0}^{N}+\lambda^{N L} X_{i t}^{L}+\lambda^{N P} X_{i t}^{P}+\lambda^{N S} X_{i t}^{S}+\lambda^{N A} X_{i t}^{A}+\mathbf{A}^{N}+\mathbf{P}^{N}+\mathbf{E}^{N}+\mathbf{D}^{N}+\eta^{N}\right) X_{i t}^{N} \\
& +\left(\beta_{0}^{L}+\lambda^{L P} X_{i t}^{P}+\lambda^{L S} X_{i t}^{S}+\lambda^{L A} X_{i t}^{A}+\mathbf{A}^{L}+\mathbf{P}^{L}+\mathbf{E}^{L}+\mathbf{D}^{L}+\eta^{L}\right) X_{i t}^{L} \\
& +\left(\beta_{0}^{A}+\lambda^{A P} X_{i t}^{P}+\lambda^{A S} X_{i t}^{S}+\eta^{A}\right) X_{i t}^{A} \\
& +\left(\beta_{0}^{P}+\lambda^{P S} X_{i t}^{S}+\eta^{P}\right) X_{i t}^{P} \\
& +\left(\beta_{0}^{S}+\eta^{S}\right) X_{i t}^{S} \\
& +\left(\beta_{0}^{B}+\mathbf{A}^{B}+\mathbf{P}^{B}+\mathbf{M}^{B}\right) X_{i t}^{B} \\
& +\varepsilon_{i t}
\end{aligned}
$$

with $\mathbf{A}^{q}, \mathbf{P}^{m}, \mathbf{E}^{k}, \mathbf{D}^{r}$ and $\mathbf{M}^{s}$ the effects coded covariate terms and $\eta^{K}(K=N, L, A, S, P)$ the individual specific preference deviations. The effects coded covariate terms are defined as 


$$
\begin{array}{ll}
\mathbf{A}^{q}=\alpha_{1}^{q} A_{1}^{\text {WTP }}+\alpha_{2}^{q} A_{2}^{\text {WTP }}+\alpha_{3}^{q} A_{1}^{\text {WTA }}+\alpha_{4}^{q} A_{2}^{\text {WTA }} & \left(\begin{array}{l}
q=N, L, B) \\
\mathbf{P}^{m}=\pi_{1}^{m} P_{1}^{\text {PrPO }}+\pi_{2}^{m} P_{3}^{\text {PrPO }}+\pi_{3}^{m} P_{1}^{\text {Expen }}+\pi_{4}^{m} P_{2}^{\text {Expen }}
\end{array}\right. \\
\mathbf{E}^{k}=\varepsilon_{1}^{k} E^{\text {PO }} & (k, L, B) \\
\mathbf{D}^{r}=\delta_{1}^{r} D^{\text {ElHeat }}+\delta_{2}^{r} D^{\text {Urban }}+\delta_{3}^{r} D^{60+}+\delta_{4}^{r} D^{\text {Home }} & (r=N, L) \\
\mathbf{M}^{s}=\mu_{1}^{s} M^{\text {Uo }}+\mu_{1}^{s} M^{M i}+\mu_{1}^{s} M^{H i} & (s=B)
\end{array}
$$

\begin{tabular}{|c|c|c|}
\hline Variable & Description & Coding \\
\hline \multicolumn{3}{|c|}{ Attitudes } \\
\hline$A_{1}^{W T P}$ & WTP more if prob. of a power outage would be reduced? & $1=$ Yes, $-1=$ Don't know, $0=$ No \\
\hline$A_{2}^{W T P}$ & WTP more if prob. of a power outage would be reduced? & 1=No, $-1=$ Don't know, $0=$ Yes \\
\hline$A_{1}^{W T A}$ & WTA more power outages if electricity bill would decrease? & $1=$ Yes, $-1=$ Don't know, $0=$ No \\
\hline$A_{2}^{W T A}$ & WTA more power outages if electricity bill would decrease? & $1=$ No, $-1=$ Don't know, $0=$ Yes \\
\hline \multicolumn{3}{|c|}{ Perception } \\
\hline$P_{1}^{\operatorname{Pr} P O}$ & In your opinion, would you expect future probability of PO to... & $1=$ Decrease,$-1=$ No change, $0=\operatorname{lncrease}$ \\
\hline$P_{3}^{\operatorname{Pr} P O}$ & In your opinion, would you expect future probability of PO to... & $1=$ Increase,$-1=$ No change, $0=$ Decrease \\
\hline$P_{1}^{\text {Expen }}$ & Perceived level of the current electricity bill & $1=$ Very low to avg., $-1=$ No opinion, $0=$ High to very high \\
\hline$P_{2}^{\text {Expen }}$ & Perceived level of the current electricity bill & 1=High to very high, $-1=$ No opinion, $0=$ Very low to avg. \\
\hline \multicolumn{3}{|c|}{ Experience } \\
\hline$E^{P O}$ & Did you experience power outages over the past 2 years? & $1=Y e s,-1=$ No \\
\hline \multicolumn{3}{|c|}{ Socio - demographics } \\
\hline$D^{60+}$ & Respondent is older than 60 & $1=60^{+},-1=$ younger than 60 \\
\hline$D^{\text {ElHeat }}$ & Household mainly uses electric heating & 1=Electr. heating, $-1=$ No electr. heating \\
\hline$D^{\text {Urban }}$ & Household lives in urban area & $1=$ Urban, $-1=$ Rural \\
\hline$D^{\text {Home }}$ & Respondent spends at lot of time at home & 1= Usually at home, $-1=$ Usually not at home \\
\hline \multicolumn{3}{|c|}{ Income } \\
\hline$M^{L o}$ & Household reports low income & $1=$ Inc. in $1^{\text {st }} Q_{.},-1=$ Unknown, $0=$ Inc. not in $1^{\text {st }} Q$. \\
\hline$M^{M i}$ & Household reports medium income & $1=$ Inc. in $2^{\text {nd }}$ or $3^{\text {rd }}$ Q., $-1=$ Unknown, $0=$ Inc. not in $2^{\text {nd }}$ or $3^{\text {rd }} Q$. \\
\hline$M^{H i}$ & Household reports high income & $1=$ Inc. in $4^{\text {th }} Q_{.,}-1=$ Unknown, $0=$ Inc. not in $4^{\text {th }} \mathrm{Q}$. \\
\hline
\end{tabular}

and further described in Table 6.

Table 6: Variable definitions and coding of the variables.

Alternative-specific constants (ASC) are added for the non-status quo alternatives. These constants capture variations in choices that cannot be explained by the attributes or by the socio-demographic covariates included in the model. As alternatives are unlabeled, we expect the parameters of these constants to be equal within each model specification. However, as discussed by Champ et al. (2003), Chapter 6, these alternative-specific constants might capture a status quo bias, thus they might be significantly different from zero. Negative values would indicate that the respondents would prefer not to move away from the status quo. See Hartman et al. (1991) and Beenstock et al. (1998) for an assessment of the status quo effect and its implications in the context of reliable electricity supply.

Note that all estimated models are nested in this general specification. The simple conditional logit model corresponds to having all interaction parameters equal to zero. The other models are extensions of this simple conditional logit specification towards the ultimate model specification 
described by equation (9). The RPL estimation procedure involved using Maximum simulated Likelihood with 500 Halton draws ${ }^{13}$.

\subsection{Discussion of the estimation results}

\section{Alternative specific constants}

As expected, all models in Table 8 show significantly negative alternative-specific effects indicating the presence of a status quo effect, i.e. respondents tend to prefer the status quo situation rather than any of the presented alternatives. Table 7 summarizes the results of a set of Wald-tests used to test the hypothesis that the parameters of the alternative-specific constants within one model specification are equal. This hypothesis is rejected at the $5 \%$ level for the main effects conditional logit model but cannot be rejected for the three other models.

\begin{tabular}{l|cc}
\hline \multicolumn{1}{c|}{ Model } & $\chi^{2}$ & Prob. $>\chi^{2}$ \\
\hline $\mathrm{CL}$ Main & 6,20 & 0,0451 \\
$\mathrm{CL}$ Main \& IA & 5,72 & 0,0573 \\
$\mathrm{RPL}$ Main \& IA & 3,47 & 0,1766 \\
Correlated RPL Main \& IA & 2,75 & 0,2534 \\
\hline \multicolumn{2}{l}{$\mathbf{H}_{0}: \mathrm{ACS}_{1}=\mathrm{ACS}_{2}=\mathrm{ACS}_{3}$. Critical $\chi$ value: $\chi_{0.05}^{2}(2)=5.99$}
\end{tabular}

Table 7: Results of a Wald test on the equality of the alternative specific constants.

\section{Main effects}

Except for the announcement and season attributes, all main effects have been estimated significantly different from zero ( $99 \%$ confidence level) in all models. Moreover, all significant parameters have the expected sign. Both the announcement and the season attributes are estimated significantly in the main effects CLM. The season attribute remains significant in the $\mathrm{CL}$ Main \& IA and the RPL Main \& IA models, but is not significant in the correlated RPL Main \& IA model. The announcement attribute is not significant in the $C L$ Main \& IA and the RPL Main \& IA model and becomes significant with opposite sign in the correlated RPL Main \& IA model. However, note that in the RPL models, the estimates of the mean of the random parameters should not be interpreted on their own. What really matters is the distribution of the preference parameter, which implies that the estimated standard deviation of the preference distribution and the estimates of the fixed parameters of the covariates with which they interact should also be considered. Taking this into account, it is more meaningful to focus on the significance of the estimates of the standard deviations or the elements of the Cholesky matrix (Table 9) which suggests that preferences for all attributes are indeed heterogeneous.

Ceteris paribus, the CLM suggests that more power outages, longer power outages, power outages during peak periods and increased electricity bills will reduce household utility. Power outages in the summer period are preferred above outages in winter periods.

13 Estimation was done with Stata v10. 


\section{Attribute interaction effects}

In general, attribute interaction effects do not play an important role in explaining household preferences. One interaction effect is systematically estimated significantly different from zero: the interaction between duration and peak/off-peak. As expected, longer power outages generate more disutility in peak periods than they do in off-peak periods.

Some interactions are systematically estimated as not significantly different from zero: number of power outages and season, duration and announcement, season and announcement, and season and peak/off-peak. The other interaction effects have varying significance depending on the model that is considered.

Focusing on the RPL model with correlated random effects, we observe that the interaction between the frequency of power outages and duration is significantly negative, which is in line with our intuition. Moreover, the interaction between the number of power outages and peak/off-peak is also negative, which is again in line with what one would expect. An increase in the number of power outages is disliked more in peak periods that it is in off-peak periods. The last interaction effect that is estimated significantly in the correlated RPL model is the interaction between announcement and peak/off-peak. The negative sign suggests that the announcement of a power outage is disliked more in peak periods than it is in off-peak periods, which is counterintuitive.

\section{Interactions with socio-demographic covariates}

A global comparison of the interaction effects between the power outage attributes and other sociodemographic covariates shows that all models generate quite similar results in terms of the parameter signs. Only a few variables were estimated with different signs in the three models. Overall, the RPL models generate more significant parameter estimates, indicating that these variables explain some of the preference heterogeneity around the mean of the random parameter with which they are interacted.

We also checked whether more complex models have more explanatory power than simpler versions. Log-likelihood ratio tests for both RPL models reject the null-hypothesis that the RPL models do not provide additional explanatory power relative to the CLM model with interactions included. Moreover, a log-likelihood ratio test that compares both RPL models allows rejecting the hypothesis that the random parameter estimates would not be correlated, i.e. the correlated RPL model outperforms the three other models.

\section{Attitude}

The variable that reflects a respondent's attitude regarding his or her willingness to pay for reducing the probability of a power outage $\left(A^{\text {WTP }}\right)$ has been interacted with the frequency, the duration and the bill attribute. A respondent with a clearly expressed negative attitude regarding his willingness to pay when the probability of power outages would be reduced, dislikes an increase in the frequency of power outages less than a respondent with unclear or positive attitudes regarding WTP. This is in line with what we would expect. Respondents that expressed a negative attitude regarding their willingness to pay, probably did so because they do not care too much about extra power outages. They will therefore incur less disutility when an extra power outage occurs.

Also for the interaction with the Bill attribute, the estimates have the expected sign. Respondents with a clearly expressed positive WTP attitude have less disutility from a higher electricity bill. 
Respondents with a clearly expressed negative WTP attitude (they do not want to pay) incur higher disutility from increased electricity bills.

Attitudes seem to be much more explicit when it comes to the question whether one is willingness to accept more power outages ( $A^{\text {WTA }}$ ) in return for a decrease in the electricity bill. Respondents with a strong positive attitude regarding their willingness to accept more power outages get less disutility from an increase in the frequency of power outages than respondents with unclear attitudes. Moreover, respondents with a strong negative attitude regarding an increase in the frequency of power outages clearly dislike an increase in the frequency of power outages more than respondents that do not have a strong opinion on this matter. A similar observation, but less significant is made with regard to the duration of power outages. Respondents that are willing to accept more power outages in return for a lower bill have fewer problems with an increase in the duration of a power outage than respondents with a vague opinion. Respondents with a clear willingness to accept an increased frequency of power outages if that would be compensated by a reduction of the electricity bill show, as can be expected, a significant disutility from an increase in the electricity bill.

\section{Perception}

The perception of respondents regarding the evolution of the likelihood of future power outages $\left(P^{\text {PrPO}}\right.$ ) has no explanatory power in the $\mathrm{CL}$ model. In both RPL models, the interaction with the electricity bill shows a significant effect. Respondents who think that the likelihood of power outages will decrease receive lower disutility from an increase in the electricity bill. Respondents that have opposite expectations receive more disutility from an increase in the electricity bill than respondents who expect an unchanged likelihood of power outages. These results might be explained by the fact that respondents are aware of the fact that increasing the reliability of the power system requires additional and costly efforts that will have to be recovered via increased electricity bills. Respondents that expect the grid quality to deteriorate would not appreciate bill increases.

The respondent's perception of the bill level does not seem to play a significant and conclusive role in explaining preferences for power outage profiles. Different models tend to give similar results, but, overall, significance is not very convincing. The RPL Main \& IA model suggests that respondents with strong (positive or negative) feelings about their electricity bill ( $\left.P^{\text {Expen }}\right)$ tend to dislike an increase in the frequency of power outages, a result that is not found in the two other models with interaction effects. Respondents that perceive their electricity bill as high to very high have less disutility from an increase in the average duration of a power outage or the electricity bill than respondents do that have no explicit opinion regarding the level of their electricity bill.

\section{PO Experience}

The results from the $C L$ and the RPL Main \& IA model suggest that households having experienced power outages over the past two year have less disutility from an increase in the frequency of power outages. This result could indicate that households having no experience with power outages overestimate the negative consequences from a power outage. Faced with a power outage, things might not seem as bad as expected. However, this result is not found in the correlated RPL model.

All models suggest that having experienced a power outage has no significant impact on the relative preferences regarding the duration of power outages. 
Socio-demographic variables

Mixed evidence in terms of significance is also found regarding the age covariate. In the $\mathrm{CL}$ as well as in the uncorrelated RPL model we find that, for a given frequency of power outages, respondents aged 60+ incur significantly more disutility than respondents aged less than 60 . This effect is not found in the correlated RPL model. However, in the latter model we find that $60+$ respondents get significantly less disutility from an increase in the average duration of a power outage than younger cohorts, again a result that is not found in the two other models.

A covariate that might by correlated with age is 'At Home'. This variable indicates whether or not a respondent is spending most of his time at home. We can expect that for respondents older than 60, this will more likely be the case than for younger cohorts. We expect that, for a given frequency of power outages or for a given average duration of power outages, respondents spending more time at home will have more disutility from a power outage. However, our estimation results do not support this conjecture.

As expected, households that use electric heating for their houses strongly dislike more and longer power outages. This effect is found in all models. In the RPL Main \& IA model, households living in urban areas (as perceived by the households) dislike an increase in the frequency of power outages more than households living in rural areas, a result which is not found in the $\mathrm{CL}$ nor in the correlated RPL model.

Finally, we find that households known to have an income in the lowest quartile tend to dislike an increased electricity bill more than households known to have an income in the second or third quartile. Households in the highest income quartile dislike paying a higher electricity bill less than those in the second or third quartile. 


\begin{tabular}{|c|c|c|c|c|c|c|c|c|}
\hline & \multicolumn{2}{|c|}{$C L$ - Main effects } & \multicolumn{2}{|c|}{$C L-M a i n$ \& IA } & \multicolumn{2}{|c|}{$R P L$ - Main \& IA } & \multicolumn{2}{|c|}{ Corr. RPL - Main \& IA } \\
\hline Variable & Coefficient & SE & Coefficient & SE & Coefficient & SE & Coefficient & SE \\
\hline ASC1 & $-1,419296 * * *$ & 0,086609 & $-1,316103 * * *$ & 0,117298 & $-0,628605^{* * *}$ & 0,119857 & $-1,042827^{* * *}$ & 0,116705 \\
\hline ASC2 & $-1,422683^{* * *}$ & 0,084281 & $-1,322310 * * *$ & 0,110659 & $-0,652804 * * *$ & 0,119347 & $-1,074515^{* * *}$ & 0,116868 \\
\hline ASC3 & $-1,518399 * * *$ & 0,085904 & $-1,414441 * * *$ & 0,111740 & $-0,740571^{* * *}$ & 0,118857 & $-1,143159 * * *$ & 0,116114 \\
\hline Num & $-0,269694 * * *$ & 0,022368 & $-0,469783^{* * *}$ & 0,101579 & $-2,841582 * * *$ & 0,303992 & $-1,372221 * * *$ & 0,200373 \\
\hline St. Dev. & & & & & $2,559336^{* * *}$ & 0,164455 & & \\
\hline Len & $-0,006207 * * *$ & 0,000388 & $-0,012583 * * *$ & 0,002914 & $\begin{array}{r}-0,018071 * * * \\
0,007634 * * *\end{array}$ & 0,003070 & $-0,022796 * * *$ & 0,003403 \\
\hline Pop (Peak=1) & $-0,154258^{* * *}$ & 0,022827 & $-0,115932^{* *}$ & 0,046169 & $-0,178304 * * *$ & 0,063510 & $-0,408935 * * *$ & 0,076412 \\
\hline St. Dev. & & & & & $0,413317^{* * *}$ & 0,044500 & & \\
\hline Sea (Summer=1) & $0,212124 * * *$ & 0,024574 & $0,187863 * * *$ & 0,048786 & $0,126111^{*}$ & 0,066132 & $-0,052745$ & 0,076181 \\
\hline St. Dev. & & & & & $-0,533442^{* * *}$ & 0,043185 & & \\
\hline Ann (Ann=1) & $0,118537^{* * *}$ & 0,022926 & 0,067868 & 0,052149 & 0,053013 & 0,064149 & $-0,137118^{*}$ & 0,073546 \\
\hline St. Dev. & & & & & $0,439379 * * *$ & 0,045168 & & \\
\hline BII & $-0,015293 * * *$ & 0,001210 & $-0,021499 * * *$ & 0,004059 & $-0,026868^{* * *}$ & 0,003193 & $-0,028001 * * *$ & 0,003359 \\
\hline NumPop & & & $-0,000501$ & 0,018869 & $-0,011984$ & 0,025077 & $-0,044793 *$ & 0,025895 \\
\hline NumSea & & & $-0,003830$ & 0,020278 & 0,024097 & 0,025252 & $-0,030522$ & 0,025009 \\
\hline NumAnn & & & 0,027444 & 0,019390 & $0,041186^{*}$ & 0,024577 & $-0,009883$ & 0,024739 \\
\hline NumLen & & & 0,000199 & 0,000274 & $-0,000181$ & 0,000312 & $-0,000649 * *$ & 0,000321 \\
\hline LenPop & & & $-0,000869 * * *$ & 0,000313 & $-0,001295^{* * *}$ & 0,000364 & $-0,001627^{* * *}$ & 0,000377 \\
\hline LenSea & & & $0,000703 * *$ & 0,000319 & $0,000798^{* *}$ & 0,000366 & 0,000542 & 0,000387 \\
\hline LenAnn & & & 0,000014 & 0,000270 & 0,000019 & 0,000354 & $-0,000207$ & 0,000366 \\
\hline AnnSea & & & 0,005863 & 0,019702 & 0,016145 & 0,028911 & $-0,030903$ & 0,029154 \\
\hline AnnPop & & & 0,005777 & 0,023976 & $-0,004051$ & 0,028076 & $-0,056279 * * *$ & 0,028269 \\
\hline PopSea & & & 0,014235 & 0,021921 & $-0,007949$ & 0,028874 & $-0,033419$ & 0,029012 \\
\hline AWTP_L1_Num & & & $0,155178^{* *}$ & 0,067959 & 0,040615 & 0,132427 & 0,054951 & 0,121048 \\
\hline AWTP_L2_Num & & & $-0,000830$ & 0,044298 & 0,042377 & 0,095865 & $0,179286 * *$ & 0,090953 \\
\hline AWTP_L1_Len & & & $-0,000552$ & 0,001021 & $-0,001715$ & 0,001365 & $-0,002866^{*}$ & 0,001692 \\
\hline AWTP_L2_Len & & & $-0,000036$ & 0,000679 & $-0,000030$ & 0,000910 & 0,002028 & 0,001274 \\
\hline AWTP_L1_BII & & & 0,003979 & 0,002470 & $0,004574 * * *$ & 0,001670 & $0,004982 * * *$ & 0,001706 \\
\hline AWTP_L2_BII & & & $-0,000608$ & 0,001773 & $-0,003086 * * *$ & 0,001160 & $-0,003260 * * *$ & 0,001211 \\
\hline AWTA_L1_Num & & & $0,132967 * * *$ & 0,042832 & $1,043679 * * *$ & 0,140701 & $0,226552 * * *$ & 0,079009 \\
\hline AWTA_L2_Num & & & $-0,082761^{* *}$ & 0,037530 & $-0,585541 * * *$ & 0,096204 & $-0,149094 * *$ & 0,070428 \\
\hline AWTA_L1_Len & & & $0,001241 *$ & 0,000650 & $0,002110 * *$ & 0,000945 & $0,002162^{* *}$ & 0,000994 \\
\hline AWTA_L2_Len & & & 0,000043 & 0,000546 & $-0,000932$ & 0,000778 & $-0,000464$ & 0,000926 \\
\hline AWTA_L1_BII & & & $-0,006611^{* * *}$ & 0,002206 & $-0,005581^{* * *}$ & 0,001299 & $-0,006519 * * *$ & 0,001345 \\
\hline AWTA_L2_BII & & & 0,002204 & 0,001756 & $-0,000536$ & 0,001013 & 0,000209 & 0,001058 \\
\hline PPrPO_L1_Num & & & $-0,071574$ & 0,064951 & $-0,378081^{* * *}$ & 0,138458 & $-0,065729$ & 0,115956 \\
\hline PPrPO_L3_Num & & & 0,014309 & 0,055738 & $0,324712^{* *}$ & 0,135552 & 0,023272 & 0,087224 \\
\hline PPrPO_L1_Len & & & $-0,000897$ & 0,001047 & $-0,000432$ & 0,001223 & $-0,001172$ & 0,001408 \\
\hline PPrPO_L3_Len & & & 0,000966 & 0,000845 & 0,000306 & 0,001023 & 0,001262 & 0,001164 \\
\hline PPrPO_L1_BII & & & 0,002345 & 0,002887 & $0,006395 * * *$ & 0,001541 & $0,005644^{* * *}$ & 0,001559 \\
\hline PPrPO_L3_BII & & & $-0,003312$ & 0,002564 & $-0,004591^{* * *}$ & 0,001385 & $-0,003774^{* * *}$ & 0,001416 \\
\hline PExpEn_L1_Num & & & $-0,119335$ & 0,085983 & $-0,474790 * *$ & 0,228002 & $-0,078680$ & 0,157635 \\
\hline PExpEn_L2_Num & & & $-0,119918$ & 0,087154 & $-0,554279 * *$ & 0,227802 & $-0,103014$ & 0,157789 \\
\hline PExpEn_L1_Len & & & 0,003585 & 0,002672 & 0,004392 & 0,002850 & 0,004964 & 0,003035 \\
\hline PExpEn_L2_Len & & & $0,004433 *$ & 0,002677 & $0,005836 * *$ & 0,002849 & $0,005782 *$ & 0,003033 \\
\hline PExpEn_L1_BII & & & 0,004298 & 0,003333 & 0,002364 & 0,002891 & 0,002574 & 0,003047 \\
\hline PExpEn_L2_BII & & & $0,005591 *$ & 0,003335 & 0,004559 & 0,002898 & $0,005271 *$ & 0,003046 \\
\hline ExperPO_Num & & & $0,172124 * * *$ & 0,043671 & $0,881406^{* * *}$ & 0,088353 & 0,039156 & 0,065798 \\
\hline ExperPo_Len & & & 0,000389 & 0,000635 & $-0,000589$ & 0,000735 & $-0,000638$ & 0,000937 \\
\hline DAge_Num & & & $-0,130746 * * *$ & 0,046602 & $-0,657868^{* * *}$ & 0,104584 & $-0,034492$ & 0,081315 \\
\hline DAge_Len & & & 0,000359 & 0,000649 & 0,000640 & 0,000779 & $0,002406^{* *}$ & 0,001029 \\
\hline DElecHeat_Num & & & $-0,136463 * * *$ & 0,045111 & $-0,294690 * * *$ & 0,075717 & $-0,146351 *$ & 0,076959 \\
\hline DElecHeat_Len & & & $-0,001267 *$ & 0,000733 & $-0,002329 * * *$ & 0,000740 & $-0,001745^{*}$ & 0,000908 \\
\hline DUrban_Nüm & & & 0,007072 & 0,026740 & $-0,167396 * * *$ & 0,060594 & $-0,011949$ & 0,055837 \\
\hline DUrban_Len & & & $-0,000725^{*}$ & 0,000393 & $-0,000249$ & 0,000537 & $-0,000903$ & 0,000666 \\
\hline DAtHome_Num & & & 0,001680 & 0,038642 & $-0,317318^{* * *}$ & 0,101996 & 0,018082 & 0,060223 \\
\hline DAtHome_Len & & & $-0,000534$ & 0,000562 & $-0,000058$ & 0,000708 & $-0,001043$ & 0,000823 \\
\hline MIncLo_BII & & & $-0,001578$ & 0,002943 & $-0,007300^{* * *}$ & 0,001676 & $-0,007884^{* * *}$ & 0,001740 \\
\hline MIncMi_BII & & & $-0,000076$ & 0,002062 & $-0,001977$ & 0,001275 & $-0,001863$ & 0,001318 \\
\hline MIncHi_BII & & & $-0,000718$ & 0,002129 & $0,003894 * * *$ & 0,001379 & $0,004593 * * *$ & 0,001429 \\
\hline Df & & & 5 & & $\overline{61}$ & & 7 & \\
\hline N & 3240 & & 3240 & & 32408 & & 3240 & \\
\hline Wald chi2 & 113 & $9^{* * *}$ & 1.29 & & & & & \\
\hline LR chi2 & & & & & 264 & & 3.02 & \\
\hline Pseudo LL & -684 & & -657 & & -525 & & -5.05 & \\
\hline AIC & 1371 & & 1325 & & 1062 & & 1026 & \\
\hline BIC & 1378 & & 1372 & & 1113 & & 1085 & \\
\hline
\end{tabular}

Table 8: Estimation results. 


\begin{tabular}{|c|c|c|c|c|c|}
\hline & Num & Len & Pop & Sea & Ann \\
\hline Num & $\begin{array}{l}-0,621512^{* * *} \\
0,071583\end{array}$ & & & & \\
\hline Len & $\begin{array}{l}-0,004439 * * * \\
0,000826 \\
\end{array}$ & $\begin{array}{l}0,005559 * * * \\
0,000899\end{array}$ & & & \\
\hline Pop & $\begin{array}{l}0,866326^{* * *} \\
0,089446\end{array}$ & $\begin{array}{l}0,007140^{* * *} \\
0,001336\end{array}$ & $\begin{array}{l}0,627036^{* * *} \\
0,060118\end{array}$ & & \\
\hline Sea & $\begin{array}{l}0,296505^{* * *} \\
0,079529\end{array}$ & $\begin{array}{l}0,001386 \\
0,000929 \\
\end{array}$ & $\begin{array}{l}0,509056^{* * *} \\
0,067407\end{array}$ & $\begin{array}{l}0,519938^{* * *} \\
0,059378\end{array}$ & \\
\hline \begin{tabular}{|l|} 
Ann \\
\end{tabular} & $\begin{array}{l}0,083398 \\
0,063374\end{array}$ & $\begin{array}{l}-0,002420^{* *} \\
0,000940\end{array}$ & $\begin{array}{l}0,553716^{* * *} \\
0,060799\end{array}$ & $\begin{array}{l}0,115884^{*} \\
0,062248\end{array}$ & $\begin{array}{l}0,234631^{* * *} \\
0,061421\end{array}$ \\
\hline
\end{tabular}

Table 9: Choleski matrix for the Correlated RPL - Main \& IA model.

\section{The willingness to pay for uninterrupted power supply}

The results presented in section 3.2 can be used to estimate household specific willingness to pay values. Although any model presented in the previous section could be used to calculate these values, we focus on WTP values based on the correlated RPL model as this model dominates the three other models presented in section 3.2. We start with a brief description of how these WTP values can be derived before actually making and discussing the calculations.

Under the assumption of a standard conditional logit model with observed utility linear in income, the consumer surplus associated with a set of alternatives takes a closed form that is easy to calculate (see also Train (2003)). The consumer surplus derived from the chosen alternative $i$ is simply the utility derived from that alternative, expressed in money terms. Knowing that a decision maker chooses the alternative that maximizes his or her utility, the consumer surplus is

$$
C S_{n}=\frac{1}{\beta_{p}} \max _{j \in C}\left(U_{n j}\right)
$$

with $\beta_{p}$ representing the preference parameters related to the monetary attributes. Dividing by $\beta_{p}$ translates utility in monetary terms. However, the researcher does not observe the utility $U_{n j}$ linked to the utility maximizing alternative. He only observes $V_{n j}$ and he knows the distribution of the error term. Therefore, only expected consumer surplus can be calculated, i.e.

$$
E\left(C S_{n}\right)=\frac{1}{\beta_{p}} E\left(\max _{j \in C}\left(V_{n j}+\varepsilon_{n j}\right)\right)
$$

McFadden (1973) and McFadden (1995) showed that, if $\varepsilon_{n j}$ is i.i.d. extreme value and utility is linear in income (i.e. $\beta_{p}$, the marginal utility of income, is constant), then this expression reduces to ${ }^{14}$

$$
E\left(C S_{n}\right)=\frac{1}{\beta_{p}} \ln \left(\sum_{j \in C} \exp \left[V_{n j}\right]\right)+K,
$$

with $K$ a number known as Euler's constant. An alternative interpretation of equation (12) is that $E\left(C S_{n}\right)$ is the average consumer surplus in the subpopulation of people who have the same

14 A more complex formulation of the change in consumer surplus is needed when the marginal utility of income is not constant. However, when marginal utility of income is constant over a range of income levels that correspond to the policy, then equation (12) can also be used (Train (2003), p. 61). 
representative utilities as consumer $n$. The total consumer surplus can then be calculated as the weighted sum of $E\left(C S_{n}\right)$ over a sample of decision makers, with the weights reflecting the numbers of people in the population who face the same representative utilities as the sampled person ( $\mathrm{Yu}$ (2003), p. 60).

The change in consumer surplus that results from a change in the alternatives and/or the choice set is then equal to

$$
\Delta E\left(C_{n}\right)=\frac{1}{\beta_{p}}\left\{\ln \left(\sum_{j \in C_{\text {After }}} \exp \left[V_{n j}^{A f t e r}\right]\right)-\ln \left(\sum_{j \in C_{\text {Before }}} \exp \left[V_{n j}^{\text {Before }}\right]\right)\right\}
$$

When the purpose is to compare two alternatives or profiles, for example the base case (the status quo) and an altered case, and if both deterministic utility terms between accolades are linear in the attributes, then equation (13) reduces to

$$
\Delta E\left(C S_{n}\right)=\frac{1}{\beta_{p}}\left\{V_{n}^{A f t e r}-V_{n}^{\text {Before }}\right\}
$$

If the purpose is to evaluate the change in one attribute and if deterministic utility is linear in the attributes, then equation (14) further reduces to the ratio of the marginal utility of the attribute and the marginal utility of income, also known as the marginal willingness to pay ${ }^{15}$. The most general expressions for the WTP estimates based on our model specification are:

$$
\begin{gathered}
W T P_{q}=-\frac{\left(\beta_{0}^{q}+\eta^{q}\right)+\sum_{\substack{m \in\{N, L, A, P, S\} \\
m \neq q}} \lambda^{q m} X^{m}+\mathbf{A}^{q}+\mathbf{P}^{q}+\mathbf{E}^{q}+\mathbf{D}^{q}}{\beta_{0}^{B}+\mathbf{A}^{B}+\mathbf{P}^{B}+\mathbf{M}^{B}} \quad(q=N, L) \\
W T P_{q}=-2 \times\left\{\begin{array}{c}
\left(\beta_{0}^{q}+\eta^{q}\right)+\sum_{\substack{m \in\{N, L, A, P, S\} \\
m \neq q}} \lambda^{q m} X^{m} \\
\frac{\beta_{0}^{B}+\mathbf{A}^{B}+\mathbf{P}^{B}+\mathbf{M}^{B}}{W}
\end{array}\right\} \quad(q=A, P, S)
\end{gathered}
$$

with $\mathbf{A}^{q}, \mathbf{P}^{q}, \mathbf{E}^{q}, \mathbf{D}^{q}, \mathbf{M}^{q}$ and $\eta^{q}$ defined as before. Using the equations (15) and (16), the marginal willingness to pay measures are fairly straightforward to derive from the parameter estimates presented in Table 8. In the equations (15) and (16), the numerator represents the marginal utility of the attribute $q$, the denominator can be interpreted as (minus) the marginal utility of income.

For models in which only main effects are estimated, the marginal willingness to pay for a change in a single quantitative attribute $q$ is defined as

$$
W T P_{q}=-\frac{\beta_{0}^{q}}{\beta_{0}^{B}} \quad(q=N, L)
$$

while for effects coded qualitative attributes, the WTP-value would be

15 Champ, Boyle et al. (2003), p. 195-196. 


$$
W T P_{q}=-2\left\{\frac{\beta_{0}^{q}}{\beta_{0}^{B}}\right\} \quad(q=A, P, S)
$$

\section{Marginal willingness to pay}

Table 11 then summarizes these marginal willingness to pay values based on the correlated RPL model for a consumer with characteristics as described in Table 10. The first line of the table contains valuation measures derived from the $C L$ Main effects model. Comparing these measures with the measures for the reference household as derived from the correlated RPL model illustrates the impact and the importance of including additional covariates that explain heterogeneity in household preferences as well as the impact of allowing for correlated random preferences.

\begin{tabular}{|ll|}
\hline Attitudes, Perception, Experience \& Socio-economic variables & \multicolumn{1}{c|}{ Reference } \\
\hline Is the respondent WTP for reduced probabilities of POs? & No \\
Is the respondent WTA more POs in return for a lower bill & No \\
Does the respondent expect a change in the future probability of a PO? & No change \\
How does the respondent evaluate the level of his/her electricity bill? & Very low to average \\
Did the respondent experience at least one PO within the past two years? & Yes \\
Does the respondent use electric heating to heat the house? & No \\
Does the respondent live in a rural or an urban area? & Urban \\
Is the respondent older or younger than 60? & Younger than 61 \\
Does the respondent spend most of his/her time at home? & No \\
What is the respondent's income level? & High income \\
Attribute & \\
\hline Annual number of power outages & 0,5 per year \\
Average duration of a power outage & 20 minutes \\
Peak / Off-peak & -1 (off-peak) \\
Season & -1 (winter) \\
Announced / Unannounced & -1 (unannounced) \\
Annual Bill (euro) & $€ 600$ per year \\
\hline
\end{tabular}

Table 10: Characteristics of the representative consumer.

The variation in WTP estimates over the different models is quite large, suggesting that taking into account interaction effects, heterogeneous preferences and correlated random effects is important in the context of explaining preferences with regard to continuous power supply in Flanders. Focusing on the $C L$ Main effects model, the estimates suggest that a Flemish household is willing to pay $€ 20,17$ to avoid having power outages in peak periods, $€ 27,74$ to have power outages in summer rather than in winter and $€ 15,50$ to have power outages announced rather than unannounced ${ }^{16}$. Moreover, a Flemish household is willing to pay $€ 17,64$ per year to avoid a one unit increase in the frequency of power outages per year and $€ 0,41$ to avoid an increase in the average duration of a power outage with one minute.

Increasing the complexity of the model by allowing for interactions and random preferences reveals the distribution of the WTP values over Flemish households. As explained before, we assume all random parameters to follow a normal distribution, implying that individual-specific preference parameters can take positive as well as negative values. As a consequence, a fraction of households is found to have negative willingness to pay values for increases in the frequency and the duration of power outages. In general, however, the estimated share of households with 'perverse' WTP values is rather small: about $16 \%$ of the Flemish households would have a negative WTP to avoid additional

\footnotetext{
16 Note that the reference period is one year. Thus all WTP values are annual payments.
} 
power outages. Similarly, we find that about $6,2 \%$ of households would be willing to pay to have an increased duration of power outages. On average, it is estimated that a reference household, as described in Table 10, would be willing to pay $€ 43,44$ to avoid one additional power outage per year. The average WTP to avoid a one minute increase in the duration of a power outage is estimated to be $€ 0,65$ per minute.

With regard to the peak/off-peak attribute, we find that $72,4 \%$ of households have a positive willingness-to pay to avoid having power outages in peak periods, implying that $27,6 \%$ would be willing to pay to have power outages in peak periods. Given our definition of the peak period (weekdays between 7am-9am and 5pm-10pm) and assuming that most households are at home at these moments, this would typically be households that prefer to be at home when power outages occur.

The WTP to have power outages in summer rather than winter ranges from - €93 (indicating a preference for power outages in winter) up to $+€ 95$ with a mean WTP value which is very close to zero. On average, households have no clear preferences about having power outages in summer or winter. About half of households are willing to pay to have outages in winter, while the other half is willing to pay to have power outages in summer.

A similar result is found for the announced/unannounced attribute for which the WTP estimates range from - $€ 85$ up to $€ 75$ euro. About $55 \%$ of households do not attach a positive value to having power outages announced in advance. This latter result is more difficult to accept from an intuitive point of view as one would expect that households prefer announced power outages over unannounced power outages ${ }^{17}$.

Table 11 also summarizes sensitivity analysis results. The first observation is that the WTP values for the qualitative attributes change, but not the proportion of the population that has a positive WTP. This result is driven by the model specification as, for the qualitative attributes, preferences and marginal utility do not depend on other attitude, perception or demographic covariates.

As expected, households in the second and the third income quartile (medium income) have lower WTP estimates for all attributes compared to households in the higher income quartile. A fortiori, this is true for households in the lowest income quartile. WTP estimates for the highest income quartile are about $50 \%$ higher compared to the WTP estimates for the lowest income quartile.

Households with a clear positive attitude regarding their willingness to pay for a reduced probability of power outages have a $67 \%$ higher WTP to avoid a power outage. Presumably, these households are well aware of the efforts required to increase power system quality and they accept that these efforts have to be paid for. A similar but even more extreme impact is found on the willingness to pay to avoid in increase in the average duration of a power interruption. In this case, these households are willing to pay about 92\% more than the reference household described in Table 10.

Households claiming to be willing to accept more power outages if this implies a lower bill have a $50 \%$ lower WTP to avoid power outages. A similar result but somewhat smaller effect is found for the WTP to avoid increased power outage duration. Again, both results are consistent with

\footnotetext{
17 A possible explanation could be that respondents, when evaluating the power outage profiles focused on other attributes such as frequency and duration to make their choice. This would explain why, except in the CL Main model, the announcement attribute is found to be insignificant with a large variation in preferences.
} 
expressed attitudes. Households claiming that they are willing to accept more power outages in return for a lower electricity bill reveal to put less weight on the quality of the power system. One can therefore expect that these households will also attach lower value to avoiding an additional power outage.

The perception of households regarding the future likelihood of power outages influences their willingness-to pay. Households expecting a decreasing likelihood of power outages on average have a 58\% higher willingness to pay to avoid power outages. Households expecting an increase in the likelihood of power outages are willing to pay $5 \%$ less than the reference household to avoid an extra power outage ${ }^{18}$. Effects of a similar order of magnitude are found for the other attributes.

Households that did not experience a power outage over the past two years (or do not remember having experienced one) have a slightly higher willingness to pay to avoid a power outage. The WTP value is $7.3 \%$ higher. The same households have a slightly lower willingness to pay to avoid a one minute increase the duration of a power outage. Again, the difference is about $7 \%$. This suggests that households having had a power outage over the past two years have noticed that the effects are not as bad as they expected a priori, if the power interruption does not last too long.

Finally, we calculated a valuation measure for households for which at least one of the household members is older than 60 and is therefore likely to spend more time at home. We expected these households to receive higher benefits from uninterrupted power supply and, therefore, that they would have a higher willingness to pay. However, the simulation results show mixed results. One the one hand, these households are, on average, willing to pay almost same amount $(+3 \%)$ to avoid an extra power failure than the reference households do. On the other hand, their willingness to pay to avoid an extra minute of power outage is about $17 \%$ lower, suggesting that these older households care less about the duration of a power outage given that one occurs.

18 Note that, in the questionnaire, this question was asked before the questions regarding their willingness to pay for improved power system quality and their willingness to accept more outages in return for a lower bill. In these last questions, it was made explicit for the respondent that increasing (decreasing) the quality of the power system would require more (less) efforts in terms of investment and maintenance and thus would be more (less) costly. 


\begin{tabular}{|c|c|c|c|c|c|}
\hline \multicolumn{6}{|c|}{ Reference $\mathrm{CL}$ - Main effects } \\
\hline Point estimate & $\begin{array}{c}\text { Off-peak } \rightarrow \text { Peak } \\
-20,17 \\
\end{array}$ & $\begin{array}{c}\text { Winter } \rightarrow \text { Summer } \\
27,74 \\
\end{array}$ & $\begin{array}{c}\text { Not Ann. } \rightarrow \text { Ann. } \\
15,50 \\
\end{array}$ & $\begin{array}{c}\text { Add. outage } \\
-17,64 \\
\end{array}$ & $\begin{array}{c}1 \text { extra minute } \\
-0,41 \\
\end{array}$ \\
\hline \multicolumn{6}{|c|}{ Reference correlated RPL } \\
\hline $\begin{array}{l}\text { Mean } \\
90 \% \text { Conf, Interval } \\
\% \text { positive }\end{array}$ & $\begin{array}{c}\text { Off-peak } \rightarrow \text { Peak } \\
-29,03 \\
(-110,62 \text { up to } 51,33) \\
27,6 \% \\
\end{array}$ & $\begin{array}{c}\text { Winter } \rightarrow \text { Summer } \\
0,98 \\
(-93,43 \text { up to } 94,98) \\
50,8 \% \\
\end{array}$ & $\begin{array}{c}\text { Not Ann. } \rightarrow \text { Ann. } \\
-4,58 \\
(-84,9 \text { up to } 75,31) \\
46,3 \% \\
\end{array}$ & $\begin{array}{c}\text { Add. outage } \\
-43,44 \\
(-116,84 \text { up to } 28,67) \\
16,0 \% \\
\end{array}$ & $\begin{array}{c}1 \text { extra minute } \\
-0,65 \\
(-1,36 \text { up to } 0,04) \\
6,2 \% \\
\end{array}$ \\
\hline \multicolumn{6}{|c|}{ Medium Income } \\
\hline $\begin{array}{l}\text { Mean } \\
90 \% \text { Conf, Interval } \\
\% \text { positive }\end{array}$ & $\begin{array}{c}\text { Off-peak } \rightarrow \text { Peak } \\
-23,16 \\
(-88,12 \text { up to } 40,98) \\
27,6 \%\end{array}$ & $\begin{array}{c}\text { Winter } \rightarrow \text { Summer } \\
0,78 \\
(-74,45 \text { up to } 75,8) \\
50,8 \%\end{array}$ & $\begin{array}{c}\text { Not Ann. } \rightarrow \text { Ann. } \\
-3,66 \\
(-67,72 \text { up to } 60,07) \\
46,3 \%\end{array}$ & $\begin{array}{c}\text { Add. outage } \\
-34,67 \\
(-92,93 \text { up to } 22,93) \\
16,0 \%\end{array}$ & $\begin{array}{c}\text { extra minute } \\
-0,52 \\
(-1,08 \text { up to } 0,03) \\
6,2 \%\end{array}$ \\
\hline \multicolumn{6}{|c|}{ Low Income } \\
\hline $\begin{array}{l}\text { Mean } \\
90 \% \text { Conf, Interval } \\
\% \text { positive }\end{array}$ & $\begin{array}{c}\text { Off-peak } \rightarrow \text { Peak } \\
-19,57 \\
(-74,44 \text { up to } 34,63) \\
27,6 \% \\
\end{array}$ & $\begin{array}{c}\text { Winter } \rightarrow \text { Summer } \\
0,65 \\
(-62,98 \text { up to } 64,01) \\
50,8 \% \\
\end{array}$ & $\begin{array}{c}\text { Not Ann. } \rightarrow \text { Ann. } \\
-3,09 \\
(-57,24 \text { up to } 50,7) \\
46,3 \% \\
\end{array}$ & $\begin{array}{c}\text { Add. outage } \\
-29,30 \\
(-78,59 \text { up to } 19,34) \\
16,0 \% \\
\end{array}$ & $\begin{array}{c}1 \text { extra minute } \\
-0,44 \\
(-0,91 \text { up to } 0,03) \\
6,2 \% \\
\end{array}$ \\
\hline \multicolumn{6}{|c|}{ Households claiming to be WTP for a reduction of PO probability } \\
\hline $\begin{array}{l}\text { Mean } \\
90 \% \text { Conf, Interval } \\
\% \text { positive }\end{array}$ & $\begin{array}{c}\text { Off-peak } \rightarrow \text { Peak } \\
-43,50 \\
(-168,3 \text { up to } 76,75) \\
27,6 \% \\
\end{array}$ & $\begin{array}{c}\text { Winter } \rightarrow \text { Summer } \\
1,52 \\
(-140,55 \text { up to } 143,28) \\
50,8 \% \\
\end{array}$ & $\begin{array}{c}\text { Not Ann. } \rightarrow \text { Ann. } \\
-6,91 \\
(-128,41 \text { up to } 113,22) \\
46,3 \%\end{array}$ & $\begin{array}{c}\text { Add. outage } \\
-72,74 \\
(-188,1 \text { up to } 35,96) \\
13,6 \% \\
\end{array}$ & $\begin{array}{c}1 \text { extra minute } \\
-1,25 \\
(-2,43 \text { up to }-0,19) \\
2,6 \% \\
\end{array}$ \\
\hline \multicolumn{6}{|c|}{ Households is WTA more power outages in return for a lower bill } \\
\hline $\begin{array}{l}\text { Mean } \\
90 \% \text { Conf, Interval } \\
\% \text { positive }\end{array}$ & $\begin{array}{c}\text { Off-peak } \rightarrow \text { Peak } \\
-23,01 \\
(-87,68 \text { up to } 40,68) \\
27,6 \% \\
\end{array}$ & $\begin{array}{c}\text { Winter } \rightarrow \text { Summer } \\
0,76 \\
(-74,12 \text { up to } 75,28) \\
50,8 \% \\
\end{array}$ & $\begin{array}{c}\text { Not Ann. } \rightarrow \text { Ann. } \\
-3,64 \\
(-67,39 \text { up to } 59,63) \\
46,3 \%\end{array}$ & $\begin{array}{c}\text { Add. outage } \\
-22,83 \\
(-80,98 \text { up to } 34,6) \\
25,6 \%\end{array}$ & $\begin{array}{c}\text { extra minute } \\
-0,43 \\
(-1 \text { up to } 0,12) \\
9,8 \% \\
\end{array}$ \\
\hline \multicolumn{6}{|c|}{ An decrease in the PO probability is expected } \\
\hline $\begin{array}{l}\text { Mean } \\
90 \% \text { Conf, Interval } \\
\% \text { positive }\end{array}$ & $\begin{array}{c}\text { Off-peak } \rightarrow \text { Peak } \\
-41,93 \\
(-162,35 \text { up to } 73,63) \\
27,6 \% \\
\end{array}$ & $\begin{array}{c}\text { Winter } \rightarrow \text { Summer } \\
1,35 \\
(-135,52 \text { up to } 137,7) \\
50,8 \% \\
\end{array}$ & $\begin{array}{c}\text { Not Ann. } \rightarrow \text { Ann. } \\
-6,65 \\
(-123,46 \text { up to } 108,78) \\
46,3 \% \\
\end{array}$ & $\begin{array}{c}\text { Add. outage } \\
-68,64 \\
(-178,74 \text { up to } 35,72) \\
14,0 \% \\
\end{array}$ & $\begin{array}{c}1 \text { extra minute } \\
-0,99 \\
(-2,09 \text { up to } 0,01) \\
5,2 \% \\
\end{array}$ \\
\hline \multicolumn{6}{|c|}{ An increase in the PO probability is expected } \\
\hline $\begin{array}{l}\text { Mean } \\
90 \% \text { Conf, Interval } \\
\% \text { positive }\end{array}$ & $\begin{array}{c}\text { Off-peak } \rightarrow \text { Peak } \\
-27,16 \\
(-103,72 \text { up to } 48,04) \\
27,6 \% \\
\end{array}$ & $\begin{array}{c}\text { Winter } \rightarrow \text { Summer } \\
0,92 \\
(-87,43 \text { up to } 88,94) \\
50,8 \% \\
\end{array}$ & $\begin{array}{c}\text { Not Ann. } \rightarrow \text { Ann. } \\
-4,30 \\
(-79,5 \text { up to } 70,35) \\
46,3 \% \\
\end{array}$ & $\begin{array}{c}\text { Add. outage } \\
-41,48 \\
(-110,43 \text { up to } 26,05) \\
15,6 \% \\
\end{array}$ & $\begin{array}{c}\text { extra minute } \\
-0,56 \\
(-1,23 \text { up to } 0,09) \\
7,9 \% \\
\end{array}$ \\
\hline \multicolumn{6}{|c|}{ No PO experience } \\
\hline $\begin{array}{l}\text { Mean } \\
90 \% \text { Conf, Interval } \\
\% \text { positive }\end{array}$ & $\begin{array}{c}\text { Off-peak } \rightarrow \text { Peak } \\
-29,03 \\
(-110,62 \text { up to } 51,33) \\
27,6 \% \\
\end{array}$ & $\begin{array}{c}\text { Winter } \rightarrow \text { Summer } \\
0,98 \\
(-93,43 \text { up to } 94,98) \\
50,8 \% \\
\end{array}$ & $\begin{array}{c}\text { Not Ann. } \rightarrow \text { Ann. } \\
-4,58 \\
(-84,9 \text { up to } 75,31) \\
46,3 \% \\
\end{array}$ & $\begin{array}{c}\text { Add. outage } \\
-46,75 \\
(-120,33 \text { up to } 25,55) \\
14,3 \% \\
\end{array}$ & $\begin{array}{c}\text { extra minute } \\
-0,60 \\
(-1,31 \text { up to } 0,1) \\
7,9 \% \\
\end{array}$ \\
\hline \multicolumn{6}{|c|}{ Older than 60 and usually at home } \\
\hline $\begin{array}{l}\text { Mean } \\
90 \% \text { Conf, Interval } \\
\% \text { positive }\end{array}$ & $\begin{array}{c}\text { Off-peak } \rightarrow \text { Peak } \\
-29,03 \\
(-110,62 \text { up to } 51,33) \\
27,6 \% \\
\end{array}$ & $\begin{array}{c}\text { Winter } \rightarrow \text { Summer } \\
0,98 \\
(-93,43 \text { up to } 94,98) \\
50,8 \%\end{array}$ & $\begin{array}{c}\text { Not Ann. } \rightarrow \text { Ann. } \\
-4,58 \\
(-84,9 \text { up to } 75,31) \\
46,3 \%\end{array}$ & $\begin{array}{c}\text { Add. outage } \\
-44,93 \\
(-118,72 \text { up to } 27,34) \\
15,3 \% \\
\end{array}$ & $\begin{array}{c}1 \text { extra minute } \\
-0,54 \\
(-1,25 \text { up to } 0,15) \\
9,9 \%\end{array}$ \\
\hline
\end{tabular}

Table 11: Marginal willingness-to pay estimates for attribute changes (in euro).

\section{Simulating a change from one power outage standard to another}

In Table 11 marginal willingness to pay values are calculated, i.e. changes in one attribute are considered, keeping all other attributes unchanged. As explained before, the estimation results can also be used to estimate changes in the consumer surplus generated by shifting from one power outage profile to another. This would be the appropriate approach when assessing, for example, a shift from the current average power outage profile (the status quo as defined before) to another average power outage profile. As an example, Table 12 considers a situation where the regulator would consider changing the current average power outage standard, implying one power outage per two years with an average duration of 20 minutes, to a new standard implying one power 
outage per year with an average duration of 10 minutes. Stated otherwise, the regulator would allow a small increase in power outage frequency in return for shorter power outage durations.

\begin{tabular}{lccc}
\hline & $\begin{array}{c}\text { Expected Change in } \\
\text { Consumer Surplus }\end{array}$ & 90\% Conf. Interval & \% Positive \\
\hline Reference Household & $-15,06$ & $(-45,83$ up to 15,92$)$ & $21,32 \%$ \\
Medium Income & $-12,02$ & $(-36,7$ up to 12,79$)$ & $21,32 \%$ \\
Low Income & $-10,27$ & $(-31,45$ up to 10,8$)$ & $21,32 \%$ \\
WTP for red prob. PO & $-23,61$ & $(-72,82$ up to 23,35$)$ & $20,47 \%$ \\
WTA more PO for lower bill & $-6,99$ & $(-32,01$ up to 17,78$)$ & $31,99 \%$ \\
Expected decrease in prob. Of PO & $-24,15$ & $(-71,07$ up to 20,89$)$ & $18,78 \%$ \\
Expected increase in prob. Of PO & $-15,04$ & $(-44,82$ up to 14,08$)$ & $19,76 \%$ \\
No PO experience & $-17,27$ & $(-48,93$ up to 13,88) & $17,99 \%$ \\
Older than 60 and mostly at home & $-16,89$ & $(-48,59$ up to 14,28) & $18,55 \%$ \\
\hline Based on the Krinsky Robb method with 1000 random draws. \\
\multicolumn{4}{c}{ Table 12: Willingness-to pay to move to another profile (in euro). }
\end{tabular}

The values in Table 12 do not take into account the status quo effect as we assume that the households have no choice ${ }^{19}$. It is the regulator who sets the new reliability standard. The results in Table 12 show that such a shift would on average result in a consumer surplus decrease for all household types in the order of magnitude of $€ 15$ to $€ 20$. Information like this can be used by regulators and other stakeholders in the industry to evaluate the appropriateness of additional investments in the power system.

\section{Creating a market for continuous power supply}

The estimation results can also be used to assess the market potential of power outage profile contracts being offered by electricity retailers or distribution companies. Technologies exist that can be used to steer the availability of electricity at the household level. As stated in the introduction, some households would prefer an increased reliability level relative to the current power outage profile (as described by the status quo), while other households would be willing to accept a reduction in the reliability level if that would be appropriately compensated by, for example, an electricity bill discount.

Table 13 and Table 14 provide an illustration. We assume that in the initial market situation one power outage profile is available, described by the status quo. In the new market situation, 10 different power outage contracts are supplied as described in Table 13. In this illustration, we focus on the trade-off between contracts having different frequency, average duration and bill attributes, i.e. the timing and announcement attributes are kept unchanged relative to the status quo situation.

19 Taking into account the status quo effect would further increase the loss in expected consumer surplus by about $€ 37$ to $€ 45$. Dividing the value of the ASC parameter by the marginal utility of income gives (approximately) $-1,07 /-0,0283 \cong € 40$. 


\begin{tabular}{ccccccc}
\hline Contract & $\begin{array}{c}\text { Frequency of } \\
\text { outages per year }\end{array}$ & $\begin{array}{c}\text { Average duration } \\
\text { of one outage }\end{array}$ & $\begin{array}{c}\text { Peak/off- } \\
\text { peak }\end{array}$ & Season & Announcement & Bill \\
\hline C1 (Status Quo) & 0.50 & $20 \mathrm{~min}$ & Off-peak & Winter & Not ann. & 600 \\
C2 & 1.00 & $20 \mathrm{~min}$ & Off-peak & Winter & Not ann. & 570 \\
C3 & 2.00 & $20 \mathrm{~min}$ & Off-peak & Winter & Not ann. & 540 \\
C4 & 0.25 & $20 \mathrm{~min}$ & Off-peak & Winter & Not ann. & 630 \\
C5 & 0.25 & $40 \mathrm{~min}$ & Off-peak & Winter & Not ann. & 600 \\
C6 & 0.50 & $10 \mathrm{~min}$ & Off-peak & Winter & Not ann. & 630 \\
C7 & 0.50 & $40 \mathrm{~min}$ & Off-peak & Winter & Not ann. & 570 \\
C8 & 0.50 & $60 \mathrm{~min}$ & Off-peak & Winter & Not ann. & 540 \\
C9 & 0.25 & $10 \mathrm{~min}$ & Off-peak & Winter & Not ann. & 660 \\
C10 & 1.00 & $40 \mathrm{~min}$ & Off-peak & Winter & Not ann. & 540 \\
\hline
\end{tabular}

Table 13: Set of power outage contracts sold in the new market.

The upper part of Table 14 shows the market shares of the contracts for the reference household when assuming that the electricity bill would not change. Essentially, this means that the different power outage contracts are provided at zero cost for household customers. The results show that the status quo contract remains the most preferred contract irrespective of the model that is used to simulate the market shares ${ }^{20}$. It has a market share of about $34 \%$ in the CL Model and $27 \%$ in the RPL model. The new outage profile contracts would all obtain a quite similar market share of about 5,5\% to $9 \%$ in the CL model. When using the RPL model to simulate, market shares show more variation, with the $4^{\text {th }}$ and $9^{\text {th }}$ contract as the most popular ones, having market shares of $12,4 \%$ and $15,0 \%$, respectively.

The reference household's change in expected consumer welfare equals - $€ 80,6$ and $-€ 37,6$ for the $\mathrm{CL}$ and the RPL model, respectively. Note that these welfare changes have been calculated by using equation (19). Applying formula (13) in the current example would create a bias due to the fact that the number of available alternatives in the initial and the new state of the world is different. This can easily be seen by observing that moving from an initial state with one profile to a new state of the world with two profiles, each being an exact copy of the initial profile, would increase welfare with a factor $\ln (2)$ despite the fact that the available options in the new and old state are identical. In general, welfare would increase with a factor $\ln \left(k_{A} / k_{B}\right)$ with $k_{B}, k_{A}$ being the number of profiles in the 'before' and the 'after' state, respectively. Therefore, we correct the reported welfare measures in Table 14 as follows:

$$
\Delta E\left(C S_{n}\right)=\frac{1}{\beta_{p}}\left\{\ln \left(\sum_{j=1}^{k_{A}} \exp \left[V_{n j n j}^{A f t e r}\right]\right)-\ln \left(\sum_{j=1}^{k_{B}} \exp \left[V_{n j n j}^{\text {Before }}\right]\right)-\ln \left(\frac{k_{A}}{k_{B}}\right)\right\}
$$

The resulting measures of welfare change can be interpreted as changes due a move from an initial state with $k_{A}$ identical status quo profiles to a final state with $k_{A}$ new and different profiles.

The second part of the table summarizes the effect of charging more or less to customers, depending on characteristics of the contract type. For the sake of simplicity, changes in the bill level are determined by applying a simple ad-hoc rule ${ }^{21}$. For the reference household, we again provide

20 For this illustration, the status quo effect is taken into account.

21 Each 'unit change' in the level of an attribute corresponding to an improved reliability level increases the bill with €30, each 'unit change' corresponding to a deterioration of reliability would decrease the bill with $€ 30$. An increase in the power outage frequency from 0.5 to 1 corresponds to 'one unit', an increase from 0.5 to 2 power outages per year corresponds to two units. Similarly, an increase in the average duration of one power outage from 20 to 40 minutes corresponds to one unit, an increase to 60 minutes corresponds to two units. 
simulation results for both the $\mathrm{CL}$ and the RPL model. Furthermore, the table also provides estimates of market shares and welfare effects for the different household types considered before. For the RPL model, the market shares can be interpreted as the percentage of households of that particular type that would opt for a particular contract. Simulation exercises like this allow assessing the sensitivity of different types of households for power outage contracts being sold in the market. For our example, the results suggest that the $1^{\text {st }}$ (status quo), $8^{\text {th }}$ and $10^{\text {th }}$ contract would for almost all household types obtain the largest market shares, although their order might differ. $\mathrm{C} 1$ is the status quo contract. Contract C8 guarantees the same frequency of outages as the status quo, but each would have on average a one-hour duration. Contract C10 implies 1 outage per year with duration of 40 minutes. Apparently, the financial compensation provided in both contracts (€60 less costly relative to the status quo contract) is sufficient to make them attractive to a significant share of the households belonging to that particular household type.

For one household type, those willing to accept more power outages in return for a lower bill, contract C3 enters the top three ranking. Not surprisingly, this contract implies 2 power outages per year with average duration of 20 minutes.

The last column of the table shows the expected change in the consumer surplus of households belonging to that specific household type. The illustration shows that the expected welfare changes vary considerably over household types.

The results in Table 14 can be used to construct aggregate measures of welfare change and aggregate market shares for the different contract types if proper weights were available. See chapter 2 in Train (2003) for a discussion of the method to do this. 


\begin{tabular}{|c|c|c|c|c|c|c|c|c|c|c|c|c|c|}
\hline & & C1 & C2 & C3 & C4 & C5 & C6 & C7 & C8 & C9 & c10 & $\Delta \mathrm{CS}$ & $\% \Delta \operatorname{Ref}$ \\
\hline & Bill & 600 & 600 & 600 & 600 & 600 & 600 & 600 & 600 & 600 & 600 & & \\
\hline \multirow[t]{2}{*}{ Ref. household (CLM Main) } & Avg & 34,4 & 7,0 & 5,4 & 8,6 & 7,6 & 8,5 & 7,1 & 6,3 & 9,1 & 6,2 & $-80,6$ & . \\
\hline & (Lo /Up) & - & - & - & - & - & - & - & - & - & - & - & \\
\hline \multirow[t]{2}{*}{ Ref. household } & $\begin{array}{c}\text { Avg } \\
\text { (Lo/Up) }\end{array}$ & $\begin{array}{c}26,5 \\
(20,2 / 31,2)\end{array}$ & $\begin{array}{c}5,7 \\
(2,0 / 10,0)\end{array}$ & $\begin{array}{c}5,0 \\
(0,1 / 21,3)\end{array}$ & $\begin{array}{c}12,4 \\
(5,9 / 18,1)\end{array}$ & $\begin{array}{c}8,7 \\
(5,4 / 11,5)\end{array}$ & $\begin{array}{c}10,7 \\
(7,1 / 13,1)\end{array}$ & $\begin{array}{c}6,5 \\
(4,4 / 8,3)\end{array}$ & $\begin{array}{c}4,9 \\
(2,3 / 8,1)\end{array}$ & $\begin{array}{c}15,0 \\
(6 / 24,5)\end{array}$ & $\begin{array}{c}4,5 \\
(1,1 / 9,4)\end{array}$ & $\begin{array}{c}-37,6 \\
(-46,6 /-27,3)\end{array}$ & - \\
\hline & Bill & 600 & 570 & 540 & 630 & 600 & 630 & 570 & 540 & 660 & 540 & & \\
\hline \multirow[t]{2}{*}{ Ref. household (CLM Main) } & Avg & 27,9 & 9,0 & 10,9 & 4,4 & 6,1 & 4,4 & 9,1 & 12,7 & 3,0 & 12,6 & $-66,97$ & \\
\hline & (Lo /Up) & - & - & - & - & - & - & - & - & - & - & - & \\
\hline Ref. household & $\begin{array}{c}\text { Avg } \\
\text { (Lo /Up ) }\end{array}$ & $\begin{array}{c}21,0 \\
(8,3 / 31,1)\end{array}$ & $\begin{array}{c}8,4 \\
(4,7 / 11,1)\end{array}$ & $\begin{array}{c}11,6 \\
(0,5 / 40,9)\end{array}$ & $\begin{array}{c}4,9 \\
(1,1 / 9,9)\end{array}$ & $\begin{array}{c}7,0 \\
(2,2 / 11,6)\end{array}$ & $\begin{array}{c}4,0 \\
(1,3 / 6,8)\end{array}$ & $\begin{array}{c}10,5 \\
(5,8 / 13)\end{array}$ & $\begin{array}{c}16,4 \\
(9,7 / 23,1)\end{array}$ & $\begin{array}{c}2,8 \\
(0,5 / 6,4)\end{array}$ & $\begin{array}{c}13,5 \\
(5,6 / 19,5)\end{array}$ & $\begin{array}{c}-26,0 \\
(-45,4 / 7)\end{array}$ & - \\
\hline No experience with PO & $\begin{array}{c}\text { Avg } \\
\text { (Lo/Up ) }\end{array}$ & $\begin{array}{c}21,0 \\
(8,7 / 30,8)\end{array}$ & $\begin{array}{c}8,1 \\
(4,4 / 10,9)\end{array}$ & $\begin{array}{c}10,6 \\
(0,5 / 37,9)\end{array}$ & $\begin{array}{c}4,9 \\
(1,2 / 10)\end{array}$ & $\begin{array}{c}7,3 \\
(2,5 / 12)\end{array}$ & $\begin{array}{c}3,9 \\
(1,3 / 6,7)\end{array}$ & $\begin{array}{c}10,8 \\
(6,3 / 13,1)\end{array}$ & $\begin{array}{c}17,3 \\
(10,4 / 24,3)\end{array}$ & $\begin{array}{c}2,8 \\
(0,5 / 6,4)\end{array}$ & $\begin{array}{c}13,3 \\
(5,4 / 19,7)\end{array}$ & $\begin{array}{c}-26,2 \\
(-45,1 / 5,4)\end{array}$ & $-0,6 \%$ \\
\hline Medium Income class & $\begin{array}{c}\text { Avg } \\
(\text { Lo /Up ) }\end{array}$ & $\begin{array}{c}17,8 \\
(4,5 / 25,6)\end{array}$ & $\begin{array}{c}8,4 \\
(5,2 / 10,5)\end{array}$ & $\begin{array}{c}13,2 \\
(0,9 / 46,9)\end{array}$ & $\begin{array}{c}3,4 \\
(0,4 / 5,7)\end{array}$ & $\begin{array}{c}5,9 \\
(1,2 / 9,5)\end{array}$ & $\begin{array}{c}2,8 \\
(0,5 / 3,9)\end{array}$ & $\begin{array}{c}10,7 \\
(4,6 / 14,1)\end{array}$ & $\begin{array}{c}20,0 \\
(12,8 / 32,3)\end{array}$ & $\begin{array}{c}1,7 \\
(0,1 / 2,6)\end{array}$ & $\begin{array}{c}16,1 \\
(9,7 / 23,9)\end{array}$ & $\begin{array}{c}-14,9 \\
(-25,2 / 20,8)\end{array}$ & $42,9 \%$ \\
\hline Low Income class & $\begin{array}{c}\text { Avg } \\
(\text { Lo /Up ) }\end{array}$ & $\begin{array}{c}14,8 \\
(4,5 / 25,6)\end{array}$ & $\begin{array}{c}8,1 \\
(5,2 / 10,5)\end{array}$ & $\begin{array}{c}14,6 \\
(0,9 / 46,9)\end{array}$ & $\begin{array}{c}2,4 \\
(0,4 / 5,7)\end{array}$ & $\begin{array}{c}5,0 \\
(1,2 / 9,5)\end{array}$ & $\begin{array}{c}2,0 \\
(0,5 / 3,9)\end{array}$ & $\begin{array}{c}10,5 \\
(4,6 / 14,1)\end{array}$ & $\begin{array}{c}23,3 \\
(12,8 / 32,3)\end{array}$ & $\begin{array}{c}1,0 \\
(0,1 / 2,6)\end{array}$ & $\begin{array}{c}18,4 \\
(9,7 / 23,9)\end{array}$ & $\begin{array}{c}-7,1 \\
(-25,2 / 20,8)\end{array}$ & $72,8 \%$ \\
\hline WTP for red. prob. PO & $\begin{array}{c}\text { Avg } \\
(\text { Lo /Up ) }\end{array}$ & $\begin{array}{c}25,8 \\
(13,3 / 33,7)\end{array}$ & $\begin{array}{c}8,0 \\
(3,6 / 11,5)\end{array}$ & $\begin{array}{c}8,7 \\
(0,3 / 33,6)\end{array}$ & $\begin{array}{c}7,7 \\
(2,3 / 13,9)\end{array}$ & $\begin{array}{c}8,0 \\
(3,3 / 11,9)\end{array}$ & $\begin{array}{c}6,6 \\
(2,8 / 9,9)\end{array}$ & $\begin{array}{c}9,4 \\
(6,3 / 11,5)\end{array}$ & $\begin{array}{c}10,6 \\
(5,7 / 16,1)\end{array}$ & $\begin{array}{c}6,0 \\
(1,4 / 12,3)\end{array}$ & $\begin{array}{c}9,3 \\
(3,0 / 15,8)\end{array}$ & $\begin{array}{c}-53,3 \\
(-81,0 /-15,7)\end{array}$ & $-104,7 \%$ \\
\hline WTA more PO for lower Bill & $\begin{array}{c}\text { Avg } \\
\text { (Lo /Up ) }\end{array}$ & $\begin{array}{c}15,5 \\
(4,2 / 27,1)\end{array}$ & $\begin{array}{c}8,6 \\
(5,3 / 10,9)\end{array}$ & $\begin{array}{c}18,1 \\
(1,2 / 55,1)\end{array}$ & $\begin{array}{c}2,8 \\
(0,4 / 6,5)\end{array}$ & $\begin{array}{c}5,0 \\
(1,1 / 9,7)\end{array}$ & $\begin{array}{c}2,4 \\
(0,5 / 4,8)\end{array}$ & $\begin{array}{c}9,8 \\
(3,8 / 13,5)\end{array}$ & $\begin{array}{c}19,3 \\
(9,5 / 27,9)\end{array}$ & $\begin{array}{c}1,3 \\
(0,2 / 3,4)\end{array}$ & $\begin{array}{c}17,3 \\
(9,1 / 22,3)\end{array}$ & $\begin{array}{c}-9,5 \\
(-31,3 / 26,4)\end{array}$ & $63,6 \%$ \\
\hline Likel. of decr. in prob. PO & $\begin{array}{c}\text { Avg } \\
\text { (Lo/Up ) }\end{array}$ & $\begin{array}{c}24,7 \\
(12,4 / 32,8)\end{array}$ & $\begin{array}{c}7,9 \\
(3,7 / 11,1)\end{array}$ & $\begin{array}{c}8,7 \\
(0,3 / 33,6)\end{array}$ & $\begin{array}{c}7,2 \\
(2,1 / 13,2)\end{array}$ & $\begin{array}{c}8,2 \\
(3,3 / 12,4)\end{array}$ & $\begin{array}{c}5,9 \\
(2,4 / 9,1)\end{array}$ & $\begin{array}{c}9,8 \\
(6,6 / 12)\end{array}$ & $\begin{array}{c}12,2 \\
(6,7 / 18,3)\end{array}$ & $\begin{array}{c}5,3 \\
(1,2 / 11,1)\end{array}$ & $\begin{array}{c}10,0 \\
(3,3 / 16,6)\end{array}$ & $\begin{array}{c}-48,4 \\
(-75,2 /-11,3)\end{array}$ & $86,0 \%$ \\
\hline Likel. of incr. in prob. PO & $\begin{array}{c}\text { Avg } \\
(\text { Lo /Up ) }\end{array}$ & $\begin{array}{c}19,8 \\
(7,6 / 30,2)\end{array}$ & $\begin{array}{c}8,2 \\
(4,7 / 10,9)\end{array}$ & $\begin{array}{c}11,7 \\
(0,5 / 40,8)\end{array}$ & $\begin{array}{c}4,4 \\
(0,9 / 9,2)\end{array}$ & $\begin{array}{c}6,8 \\
(2,1 / 11,6)\end{array}$ & $\begin{array}{c}3,5 \\
(1,1 / 6,2)\end{array}$ & $\begin{array}{c}10,7 \\
(5,8 / 13,3)\end{array}$ & $\begin{array}{c}18,2 \\
(10,8 / 25,6)\end{array}$ & $\begin{array}{c}2,4 \\
(0,4 / 5,6)\end{array}$ & $\begin{array}{c}14,3 \\
(6,1 / 20,5)\end{array}$ & $\begin{array}{c}-22,1 \\
(-41,9 / 9,7)\end{array}$ & $15,2 \%$ \\
\hline $60+\&$ usually at home & $\begin{array}{c}\text { Avg } \\
\text { (Lo/Up) }\end{array}$ & $\begin{array}{c}20,4 \\
(8,3 / 30,3)\end{array}$ & $\begin{array}{c}8,1 \\
(4,5 / 10,7)\end{array}$ & $\begin{array}{c}10,9 \\
(0,5 / 38,8)\end{array}$ & $\begin{array}{c}4,8 \\
(1,1 / 9,7)\end{array}$ & $\begin{array}{c}7,2 \\
(2,4 / 12,0)\end{array}$ & $\begin{array}{c}3,8 \\
(1,3 / 6,5)\end{array}$ & $\begin{array}{c}10,8 \\
(6,1 / 13,2)\end{array}$ & $\begin{array}{c}17,8 \\
(10,7 / 24,9)\end{array}$ & $\begin{array}{c}2,7 \\
(0,5 / 6,1)\end{array}$ & $\begin{array}{c}13,6 \\
(5,6 / 19,9)\end{array}$ & $\begin{array}{c}-25,1 \\
(-44,4 / 7,2)\end{array}$ & $3,7 \%$ \\
\hline
\end{tabular}

Table 14: Market shares of power outage contracts and impact on consumer surplus ( $\triangle \mathrm{CS}$ ) for varying household types. 


\section{Summary and conclusions}

This paper tackles the question whether and to what extent Flemish households are willing to pay for uninterrupted power supply or, stated differently, how much they are willing to accept for decreased reliability levels. The data were collected via choice experiments which were then used to estimate a set of logit models ranging from a main effects conditional logit model to random parameter logit model with interaction effects and correlated preferences. Power outages are characterized by 6 attributes: annual frequency, duration, peak or off peak, announced or unannounced, winter or summer and invoice impact.

The estimation results are in line with prior expectations and show that households do value the different characteristics of a power outage. Moreover, the results support the hypotheses that preferences for all power attributes are heterogeneous and that the mean parameters for frequency and duration depend on attitude, perception, experience and socio-demographic characteristics. The model estimates also reveal the presence of a significant status quo effect, since households prefer not to change to another power outage profile.

The estimates are then used to assess the marginal willingness to pay by Flemish households for each of the power outage attributes. The results suggest that the mean willingness to accept for a one unit increase in the average frequency of power outages is in the order of magnitude of $€ 30$ to $€ 50$ per year for most household types, while the marginal willingness-to-accept for a one minute increase in the average duration of power outages lies in the range $€ 0,40$ to $€ 0,60$ per minute per year. Overall, the estimates suggest that Flemish households have heterogeneous preferences regarding power outage attributes and that a significant share of them is willing to switch to a lower reliability level if that would be compensated by a relatively small electricity bill discount.

The distribution of preferences for the season and announcement attributes is less clear. About half of the sample prefers power outages to occur in summer rather than in winter. Again, about half of the sample prefers power outages not to be announced, a result that is counterintuitive. With regard to the timing of power outages within the day, about $75 \%$ of households prefer power outages to occur in off-peak periods. On average, households are willing to pay about $€ 30$ per year to have power outages in off-peak rather than in peak periods.

The paper also illustrates expected changes in consumer surplus when moving to another power outage profile (for example imposed by a regulator) or when moving to a market in which power outage profile contracts are being sold. These illustrations show that, despite the status quo effect, a significant percentage of households would actually be willing to switch to another power outage profile in return for compensation that remains within an acceptable range of about $5 \%$ to $10 \%$ of the electricity bill.

From a policy perspective, the results are interesting as they suggest that a not too small proportion of Flemish households would be willing to switch to another power outage profile in return for an affordable compensation. The social benefit would be found in the grid and power station investment outlays that can be avoided by using lower reliability standards. Moreover, the same type of information can also be used by retailers and other private firms that sell electricity services such as power with different reliability characteristics.

One of the major shortcomings of this paper is the assumption of normally distributed preferences for frequency and duration, yielding unreasonable (i.e. negative) WTP-estimates for a non-negligible 
fraction of the population. Future research based on this data should focus on estimating models with more appropriate assumptions regarding the distribution of these preferences.

\section{Acknowledgements}

The author would like to thank Mehdi Farsi, Gerd Küpper, Sandra Rousseau, David Ryan and Frank Verboven for helpful comments and discussions. 


\section{REFERENCES}

Ajodhia, V., Hakvoort, R., 2005. Economic regulation of quality in electricity distribution networks. Utilities Policy. 13. 211-221.

Amaya-Amaya, M., Gerard, K., Ryan, M., 2008. Discrete Choice Experiments in a Nutshell, Using Discrete Choice Experiments to Value Health and Health Care, pp. 13-46.

Bateman, I.J., Carson, R.T., Day, B., Hanemann, M., Hanley, N., Hett, T., Jones-Lee, M., Loomes, G., Moureto, S., Özdemiroglu, E., Pearce, D.W., Sudgen, R., Swanson, J., 2002. Economic Valuation with Stated Preference Techniques: A Manual, $1^{\text {st }}$ ed., Edward Elgar, Cheltenham.

Beenstock, M., Goldin, E., Haitovsky, Y., 1998. Response bias in a conjoint analysis of power outages. Energy Economics. 20. 135-156.

Boxall, P.C., Adamowicz, W.L., 2002. Understanding Heterogeneous Preferences in Random Utility Models: A Latent Class Approach. Environmental and Resource Economics. 23. 421-446.

Carlsson, F., Martinsson, P., 2006. Do Experience and Cheap Talk influence Willingness to Pay in an Open-Ended Contingent Valuation Survey?, p. 18.

Carlsson, F., Martinsson, P., 2008. Does it matter when a power outage occurs? -- A choice experiment study on the willingness to pay to avoid power outages. Energy Economics. 30. 1232-1245.

Champ, P.A., Boyle, K.J., Brown, T.C., 2003. A Primer on Nonmarket Valuation, $1^{\text {st }}$ ed., Kluwer Academic Publishers, Dordrecht.

Council of European Energy Regulators. 2009. 4th Benchmark report on quality of electricity supply 2008, p. 200.

Hartman, S., Doane, M.K., Woo, C.K., 1991. Consumer Rationality and the Status Quo. Quarterly Journal of Economics. 106. 141-162.

Hensher, D., Greene, W.H., 2003. The mixed logit model: the state of practice. Transportation. 30. 133.

Hole, A.R., 2007. A comparison of approaches to estimating confidence intervals for willingness to pay measures. Health Economics. 16. 827-840.

Horowitz, J.K., McConnell, K., 2002. A review of WTA/WTP studies. Journal of Environmental Economics and Management. 44. 426.

Hsu, G.J.Y., Chang, P.L., Chen, T.y., 1994. Various methods for estimating power outage costs - Some implications and results in Taiwan. Energy Policy. 22. 69-74.

Kuhfeld, W.D., 2004. Marketing Research Methods in SAS: Experimental Design, Choice, Conjoint, and Graphical Techniques, Cary, NC, p. 782.

Louvière, J.J., Hensher, D., Swait, J.D., 2003. Stated Choice Methods: Analysis and Application, 2 ed., Cambridge University Press, Cambridge.

McFadden, D., 1973. Conditional Logit Analysis of Qualitative Choice Behaviour, In: Zaremba, P. (Ed), Frontiers in Econometrics. Academic Press, New York, pp. 105-142.

McFadden, D., 1995. Computing Willingness-to-pay in Random Utility Models, Department of Economics, Berkeley, p. 30.

McFadden, D., Train, K., 2000. Mixed MNL models for discrete response. Journal of Applied Econometrics. 15. 447-470.

Moore, R., 2008. Using Attitudes to Characterize Heterogeneous Preferences University of Georgia, p. 36.

Morey, E., Rossmann, K.G., 2003. Using Stated-Preference Questions to Investigate Variations in Willingness to Pay for Preserving Marble Monuments: Classic Heterogeneity, Random Parameters, and Mixture Models. Journal of Cultural Economics. 27. 215-229.

Morey, E., Thacher, J., Breffle, W., 2006. Using Angler Characteristics and Attitudinal Data to Identify Environmental Preference Classes: A Latent-Class Model. Environmental and Resource Economics. 34. 91-115. 
Munasinghe, M., Sanghvi, A., 1988. Reliability of electricity supply, outage costs and value of service: an overview. Energy Journal. 9. 1-18.

Provencher, B., Bishop, R.C., 2004. Does accounting for preference heterogeneity improve the forecasting of a random utility model? A case study. Journal of Environmental Economics and Management. 48. 793-810.

Serra, P., Fierro, G., 1997. Outage Costs in Chilean industry. Energy Economics. 19. 417-434.

Train, K.E., 2003. Discrete Choice Methods with Simulations, 1 ed., Cambridge University Press, Cambridge.

VREG. 2008. Rapport van de Vlaamse Reguleringsinstantie voor de Elektriciteits- en Gasmarkt met betrekking tot de kwaliteit van de dienstverlening van de elektriciteitsdistributienetbeheerders in het Vlaamse Gewest in 2007 Brussel, p. 28.

$\mathrm{Yu}, \mathrm{Z}$., 2003. A market power model with price caps and compact DC power flow constraints. International Journal of Electrical Power \& Energy Systems. 25. 301-307. 


\section{Appendix A}

In the table below you can find some power outage scenarios. Each scenario can be interpreted as a minimum quality objective that your electricity company should achieve in the next year. Each scenario also implies an effect on your annual electricity bill. Indicate, for each of the 12 choice sets, what scenario you would prefer. You can also choose to keep the current situation.

Draw a circle around the preferred scenario.

\begin{tabular}{|c|c|c|c|c|c|c|c|}
\hline Block & Scenario & $\begin{array}{l}\text { Frequency } \\
\text { of PO per } \\
\text { year }\end{array}$ & $\begin{array}{c}\text { Duration of } \\
\text { the PO }\end{array}$ & Season & Timing & Announced & Change in Bill \\
\hline 4.1 & $A$ & 4 & $15 \mathrm{~min}$. & Winter & Peak & Yes & $10 \%$ reduction \\
\hline 4.1 & B & 4 & $15 \mathrm{~min}$. & Summer & Off-peak & No & No effect \\
\hline 4.1 & C & 1 & $15 \mathrm{~min}$. & Summer & Peak & No & No effect \\
\hline 4.1 & $\mathrm{D}$ & \multicolumn{6}{|c|}{ You prefer the current situation } \\
\hline \multicolumn{8}{|c|}{$\ldots$} \\
\hline Block & Scenario & $\begin{array}{l}\text { Frequency } \\
\text { of PO per } \\
\text { year }\end{array}$ & $\begin{array}{c}\text { Duration of } \\
\text { the PO }\end{array}$ & Season & Timing & Announced & Change in Bill \\
\hline 4.12 & A & 4 & $30 \mathrm{~min}$. & Summer & Peak & Yes & $10 \%$ reduction \\
\hline 4.12 & B & 4 & $30 \mathrm{~min}$. & Winter & Peak & Yes & No effect \\
\hline 4.12 & C & 4 & $4 \mathrm{hrs}$ & Summer & Off-peak & Yes & $10 \%$ reduction \\
\hline 4.12 & D & \multicolumn{6}{|c|}{ You prefer the current situation } \\
\hline
\end{tabular}

Table 15: Extract taken from one block of 12 choice sets. 